\title{
Synaptic Contributions to Receptive Field Structure and Response Properties in the Rodent Lateral Geniculate Nucleus of the Thalamus
}

\author{
Vandana Suresh, ${ }^{1}$ Ulaş M. Çiftçioğlu, ${ }^{1}$ Xin Wang, ${ }^{2}$ Brittany M. Lala, ${ }^{1}$ Kimberly R. Ding, ${ }^{1}$ William A. Smith, ${ }^{1}$ \\ Friedrich T. Sommer, ${ }^{3}$ and Judith A. Hirsch ${ }^{1}$ \\ ${ }^{1}$ Department of Biological Sciences and Neuroscience Graduate Program, University of Southern California, Los Angeles, California 90089-2520, \\ ${ }^{2}$ Computational Neurobiology Laboratory, The Salk Institute for Biological Studies, La Jolla, California 92037, and ${ }^{3}$ Redwood Center for Theoretical \\ Neuroscience, University of California, Berkeley, Berkeley, California 94720-3198
}

\begin{abstract}
Comparative physiological and anatomical studies have greatly advanced our understanding of sensory systems. Many lines of evidence show that the murine lateral geniculate nucleus (LGN) has unique attributes, compared with other species such as cat and monkey. For example, in rodent, thalamic receptive field structure is markedly diverse, and many cells are sensitive to stimulus orientation and direction. To explore shared and different strategies of synaptic integration across species, we made whole-cell recordings in vivo from the murine LGN during the presentation of visual stimuli, analyzed the results with different computational approaches, and compared our findings with those from cat. As for carnivores, murine cells with classical center-surround receptive fields had a "push-pull" structure of excitation and inhibition within a given On or Off subregion. These cells compose the largest single population in the murine LGN $(\sim 40 \%)$, indicating that push-pull is key in the form vision pathway across species. For two cell types with overlapping On and Off responses, which recalled either W3 or suppressed-by-contrast ganglion cells in murine retina, inhibition took a different form and was most pronounced for spatially extensive stimuli. Other On-Off cells were selective for stimulus orientation and direction. In these cases, retinal inputs were tuned and, for oriented cells, the second-order subunit of the receptive field predicted the preferred angle. By contrast, suppression was not tuned and appeared to sharpen stimulus selectivity. Together, our results provide new perspectives on the role of excitation and inhibition in retinothalamic processing.
\end{abstract}

Key words: in vivo; inhibition; LGN; relay cell; whole-cell

\section{Significance Statement}

We explored the murine lateral geniculate nucleus from a comparative physiological perspective. In cat, most retinal cells have center-surround receptive fields and push-pull excitation and inhibition, including neurons with the smallest (highest acuity) receptive fields. The same is true for thalamic relay cells. In mouse retina, the most numerous cell type has the smallest receptive fields but lacks push-pull. The most common receptive field in rodent thalamus, however, is center-surround with push-pull. Thus, receptive field structure supersedes size per se for form vision. Further, for many orientation-selective cells, the secondorder component of the receptive field aligned with stimulus preference, whereas suppression was untuned. Thus, inhibition may improve spatial resolution and sharpen other forms of selectivity in rodent lateral geniculate nucleus.

\section{Introduction}

Comparative physiological and anatomical studies highlight both shared and different neural strategies for processing information

Received March 29, 2016; revised July 29, 2016; accepted Aug. 17, 2016.

Author contributions: V.S. and J.A.H. designed research; V.S., U.M.C., and X.W. performed research; U.M.C. and F.T.S. contributed unpublished analytic tools; V.S., B.M.L., K.R.D., and W.A.S. drew labeled cells;V.S. and J.A.H. wrote the paper.

This work was supported by National Institutes of Health EY09593 to J.A.H. We thank Dr. Gregory D. Field for comments on the manuscript, and Varun Awasthi for assistance with signal analysis.

The authors declare no competing financial interests. about the environment. Here, we evaluate response properties in the murine lateral geniculate nucleus (LGN) from this perspective. In carnivores and primates, orientation and direction selectivity, by and large, first emerge in cortex (Hubel and Wiesel, 1962, 1968; Chapman et al., 1991; Cheong et al., 2013) but are

Correspondence should be addressed to Dr. Judith A. Hirsch, Department of Biological Sciences, University of Southern California, 3641 Watt Way, HNB 503, MC 2520, Los Angeles, CA 90089-2520. E-mail: jhirsch@usc.edu. DOI:10.1523/JNEUROSCI.1045-16.2016

Copyright $\odot 2016$ the authors $\quad 0270-6474 / 16 / 3610949-15 \$ 15.00 / 0$ 
encoded as early as retina in rodent (Weng et al., 2005; Girman and Lund, 2010; Zhao et al., 2013). There are also pronounced differences in receptive field structure across taxa. For example, in carnivore retina (Kuffler, 1953; Enroth-Cugell and Robson, 1984), LGN (Hubel and Wiesel, 1961; Wang et al., 2007), and cortical layer 4 (Hubel and Wiesel, 1962; Martinez et al., 2005), most receptive fields are constructed from segregated On and Off subregions with a push-pull arrangement of synaptic excitation and inhibition, characteristics important for detecting contrast borders among other functions. In mouse, this type of receptive field does not predominate in retina (Berson, 2008) and is absent at the level of cortex (Liu et al., 2009; Lien and Scanziani, 2013). The synaptic structure of receptive fields in the rodent LGN is unknown.

How does the rodent LGN compare with that of higher species, such as cat? The murine LGN retains many anatomical (Lam et al., 2005; Krahe et al., 2011) and physiological hallmarks (Montero et al., 1968; Williams et al., 1996; Grubb and Thompson, 2003; Lam et al., 2005) of carnivoran thalamus (Friedlander et al., 1981; Sherman, 2004; Usrey and Alitto, 2015). Morphologically, there are murine correlates of $X, Y$, and $W$ type cells (Lam et al., 2005; Krahe et al., 2011); physiologically, some relay cells have classical center-surround receptive fields (Grubb and Thompson, 2003; Piscopo et al., 2013; Zhao et al., 2013). However, there are substantial species differences. The smallest receptive fields are not concentrated centrally, as in carnivore and primate, and receptive field structure is diverse (Piscopo et al., 2013). Additionally, many cells are sensitive to stimulus orientation or direction (Marshel et al., 2012; Piscopo et al., 2013; Scholl et al., 2013; Zhao et al., 2013; Roth et al., 2016; Tang et al., 2016). Furthermore, while the arbors of local interneurons in carnivore (Sutton and Brunso-Bechtold, 1991; Sherman, 2004) are spatially compact, those in rodent traverse large areas of retinotopic space (Zhu et al., 1999; Seabrook et al., 2013). It is therefore unclear whether they can generate a localized form of inhibition that push-pull requires.

To explore synaptic integration in the rodent thalamus, we made patch recordings with dye-filled electrodes during vision and analyzed our results with computational approaches adapted for intracellular signals (Wang et al., 2007). These included spiketriggered averaging (STA) and spike-triggered covariance analysis (STC) (Schwartz et al., 2006) and linear-nonlinear (LN) cascade models (Simoncelli et al., 2004). Like cat, murine relay cells with center-surround receptive fields had stereotyped, albeit weaker, push-pull responses and processed their inputs in an approximately linear fashion. For other cells, including On-Off cells of various sorts (Piscopo et al., 2013), the pattern of excitation and inhibition varied with class. Different from cat, the population of cells with the smallest receptive fields were On-Off rather than center-surround, suggesting species differences in achieving high visual acuity.

We also explored the synaptic basis of orientation and direction sensitivity and found that retinogeniculate inputs themselves were tuned. Conversely, suppression was not orientation-selective and seemed to sharpen tuning of the suprathreshold response, as described for rodent cortex (Li et al., 2012). Unlike cortex, however, where the geometry of the first-order component of the receptive field (STA) predicts neural preference for stimulus angle, the STAs of orientation-tuned cells in the LGN were circular; only higher-order components of the receptive fields (STCs) predicted the optimal orientation. All told, our work provides insights into the emergence of feature selectivity in the murine visual pathway and highlights evolutionarily conserved as well as divergent elements of thalamic circuitry.

\section{Materials and Methods}

\section{Preparation}

The experimental subjects were adult (of either sex), pigmented mice (C57BL/6) and rats (Long-Evans). For rats, anesthesia was induced with a mixture of ketamine and dexmedetomidine $(4.5 \mathrm{mg} / \mathrm{kg}+0.18 \mathrm{mg} / \mathrm{kg}$, i.m.) and maintained by injections of the mixture $(0.05 \mathrm{ml})$ every $45 \mathrm{~min}$ or as necessary. Mice were sedated with chlorprothixene $(5 \mathrm{mg} / \mathrm{kg})$; then anesthesia was initiated and maintained with urethane $(0.5-1 \mathrm{~g} / \mathrm{kg} 10 \%$ w/v in saline, i.p.) (Niell and Stryker, 2008). Body temperature was measured using a rectal probe and maintained at $37^{\circ} \mathrm{C}$. After retracting the scalp, a headpost was affixed to the skull and a small craniotomy centered over the LGN was made. Durotomies were necessary in rats but not mice, and the brain and eyes were kept moist with saline. All procedures were in accord with the guidelines of the National Institutes of Health and the Institutional Animal Care and Use Committees of the University of Southern California.

\section{Recordings}

Whole-cell recordings with biocytin-filled pipettes were made using previously described techniques (Hirsch et al., 2003; Hirsch and Martinez, 2006; Wang et al., 2007) and, unless otherwise noted, the membrane was held just below the threshold for firing (determined in the absence of a visual stimulus) to help reveal inward and outward currents. Pipette resistance varied between 5 and 20 Mohms. Neural signals were recorded using an Axopatch 200A amplifier (Axon Instruments), digitized at 10 $\mathrm{kHz}$ (Power 1401 data acquisition system, Cambridge Electronic Design) and stored for further analysis (Wang et al., 2007, 2011).

\section{Visual stimuli}

Our stimulus set included discs (3-20 degrees) and annuli (inner diameter: 5-25 degrees and outer diameter: 80-100 degrees); sparse noise (dark and bright squares (2-20 degrees, contrast 50\%) displayed 16 times each on a $16 \times 16$ pixel grid in pseudo random order (Jones et al., 1987); drifting sinusoid gratings (temporal frequency: $3-4 \mathrm{~Hz}$, spatial frequency: 0.01-0.1 cycles/degree, 8 directions, full contrast); and 2D Gaussian white noise stimulus ( $33 \%$ RMS contrast, pixel size 1, 3, 5, or 7 degrees). The frame rate for noise was $35 \mathrm{~Hz}$. Images were generated with a stimulus generator (ViSaGe, Cambridge Research Systems) and displayed on a gamma-corrected LCD monitor (Dell U2211H) with a refresh rate of $70 \mathrm{~Hz}$.

\section{Event sorting and detection}

To detect potential neural events, we applied an adaptive threshold to the first derivative of the intracellular signal such that the smallest potential events included both EPSCs and noise. These events were then sorted using an algorithm based on a support vector machine (SVM) (Chang and Chih-Jen, 2011) trained with randomly selected events that were manually labeled as EPSCs or noise. The first derivative and the value of the derivative following three consecutive steps of downsampling were computed for the labeled dataset and supplied as features to the SVM. The SVM yielded two clusters: noise and neural events. Because events near the decision boundary were prone to misclassification, we labeled these manually for additional training and then reclassified the dataset. Finally, spikes were sorted from the EPSCs by repeating the algorithm exclusively on SVM-classified neural events.

\section{Measuring the spatial distribution of excitation versus inhibition} in the receptive field

Excitation/inhibition (E\I) symmetry index. To help separate push-pull responses from other types, we measured the net inward or outward extent of membrane currents evoked by sparse noise after removing action currents (MATLAB: medfilt2 function, The MathWorks) (Wang et al., 2007). Responses to bright and dark spots for locations within the center of the receptive field were averaged and then normalized (Martinez et al., 2005). We made a metric called the E\I symmetry index, $\alpha$, to describe cells based on their synaptic response to On and Off stimuli as follows: 


$$
\mathrm{f}(\alpha)=\operatorname{argmin}_{\alpha} \sum_{\mathrm{t}=1}^{\mathrm{N}}|\mathrm{P}(\mathrm{t})+\alpha * \mathrm{~N}(\mathrm{t})|^{2}
$$

Here, $\mathrm{P}$ and $\mathrm{N}$ are the synaptic responses to bright and dark spots, respectively. Values of $\alpha \geq 0$ represent cells that are excited by stimuli of one polarity and inhibited by stimuli of the opposite polarity, whereas values of $\alpha \leq 0$ represent cells for which both bright and dark spots evoke responses of the same sign.

Bright-dark response polarity score. To score the sign of the response to bright and dark spots presented within the receptive field of single cells, we made a simple bright-dark response polarity index, or $(\Omega)$ as follows:

$$
\begin{aligned}
& \Omega_{\text {Bright }}=\frac{R_{\text {max }}(\text { Bright })}{\sqrt{R_{\text {max }}^{2}(\text { Bright })+R_{\text {max }}^{2}(\text { Dark })^{2}}} \\
& \Omega_{\text {Dark }}=\frac{R_{\text {max }}(\text { Dark })}{\sqrt{R_{\max }^{2}(\text { Bright })^{2}+R_{\max }^{2}(\text { Dark })^{2}}}
\end{aligned}
$$

where $\mathrm{R}_{\max }$ is the peak or trough of the normalized response to bright or dark spots.

$\Omega_{\text {Bright }}$ and $\Omega_{\text {Dark }}$ values lie on a unit circle. When bright and dark spots evoke responses of the same sign, whether excitatory or suppressive, $\Omega_{\text {Bright }}$ and $\Omega_{\text {Dark }}$ have the same polarity, the index values occupy the first or third quadrants of the unit circle. On the contrary, if bright and dark spots evoke responses of the opposite sign, $\Omega_{\text {Bright }}$ and $\Omega_{\text {Dark }}$ have opposite polarities and the index values occupy the second or fourth quadrants of the unit circle.

Receptive field size. To measure receptive field size, we used standard techniques (Wang et al., 2007). We fit the sparse noise maps with 2D Gaussians to obtain the radius of the subregions. We report values (mean $\pm \mathrm{SD}$ ) for the center subregion for cells with a center-surround organization and for a single subregion for On-Off cells.

\section{Measuring orientation and direction selectivity}

The strength of orientation and direction tuning in response to drifting gratings was quantified using the orientation selectivity index (OSI) and direction selectivity index (DSI), respectively (Piscopo et al., 2013; Zhao et al., 2013), as follows:

$$
\begin{gathered}
\text { OSI }=\frac{\sqrt{\left(\sum_{\mathrm{i}=0}^{7} \rho_{\mathrm{i}} * \operatorname{Sin}\left(\frac{\mathrm{i} * \pi}{4}\right)\right)^{2}+\left(\sum_{\mathrm{i}=0}^{7} \rho_{\mathrm{i}} * \operatorname{Cos}\left(\frac{\mathrm{i} * \pi}{4}\right)\right)^{2}}}{\sum_{\mathrm{i}=0}^{7} \rho_{\mathrm{i}}} \\
\text { DSI }=\frac{\sqrt{\left(\sum_{\mathrm{i}=0}^{7} \rho_{\mathrm{i}} * \operatorname{Sin}\left(\frac{\mathrm{i} * \pi}{4}\right)\right)^{2}+\left(\sum_{\mathrm{i}=0}^{7} \rho_{\mathrm{i}} * \operatorname{Cos}\left(\frac{\mathrm{i} * \pi}{4}\right)\right)^{2}}}{\sum_{\mathrm{i}=0}^{7} \rho_{\mathrm{i}}} \\
\rho_{\mathrm{i}}=\frac{\mathrm{R}_{\frac{\mathrm{i}}{4} \pi}}{\mathrm{R}_{\max }} 0 \leq \mathrm{i} \leq 7
\end{gathered}
$$

Here $\mathrm{R}_{\mathrm{i} * \pi / 4}$ is the average response to gratings drifting in the direction given by $i^{*} \pi / 4$, and $\mathrm{R}_{\max }$ is the response to the direction that evoked the maximum event rate.

We also assessed the contribution of suppression to orientation selectivity from responses to drifting gratings by measuring the area defined by the net outward current above baseline during a fixed time window (results computed with a variable time window were similar). The OSI for suppression was calculated using Equation 6 by replacing $\rho_{\mathrm{i}}$ with the following:

$$
\rho_{\mathrm{s}, \mathrm{i}}=\frac{\int_{\mathrm{t} 1}^{\mathrm{t} 2} \frac{\mathrm{R}_{i} * \pi}{4}(\mathrm{t}) \mathrm{dt}}{\mathrm{R}_{\mathrm{S}, \max }} 0 \leq \mathrm{i} \leq 7
$$

Estimating subunits of the receptive field

First- and second-order subunits of the receptive fields were recovered using standard methods of STA and STC analysis (Schwartz et al., 2006; Vaingankar et al., 2012) modified to ensure that the STAs and STCs are independent (Schwartz et al., 2006; Vaingankar et al., 2012). The significance of the STC subunits was assessed with a nested bootstrap method (Schwartz et al., 2006; Vaingankar et al., 2012). To estimate receptive field subunits from the retinal input, the analysis was repeated with EPSCs. The first- and second-order filters in this case were called the EPSC-triggered average (ETA) and the EPSC-triggered covariance (ETC) filters, respectively.

Subunits of the receptive field that were circular were fit with a Gaussian function as follows:

$$
\mathrm{F}(\mathrm{x}, \mathrm{y})=\frac{\mathrm{A}}{2 \pi \mathrm{ab}} \exp \left(-\frac{\mathrm{x}^{\prime 2}}{2 \mathrm{a}^{2}}-\frac{\mathrm{y}^{\prime 2}}{2 \mathrm{~b}^{2}}\right)
$$

where $\mathrm{A}$ is the maximum amplitude, $\mathrm{a}$ and $\mathrm{b}$ are the semi-major and -minor axes respectively, and $x^{\prime}$ and $y^{\prime}$ are the transformations of the stimulus coordinates $x$ and $y$, taking into account the angle $\theta$ and the offset of the ellipse (Martinez et al., 2005).

Subunits with adjacent, elongated, subfields were fit using a Gabor function as follows:

$$
\begin{gathered}
\mathrm{G}(\mathrm{x}, \mathrm{y})=\mathrm{F}(\mathrm{x}, \mathrm{y}) * \mathrm{H}(\mathrm{x}, \mathrm{y}) \\
\mathrm{H}(\mathrm{x}, \mathrm{y})=\operatorname{Cos}[-2 \pi(\mathrm{U} * \mathrm{x}+\mathrm{V} * \mathrm{y})-\mathrm{P}]
\end{gathered}
$$

where $\mathrm{U}$ and $\mathrm{V}$ are the spatial frequencies in the $x$ and $y$ directions and $\mathrm{P}$ is the phase.

\section{Determining the circularity of the STA and STC subunits}

We devised a metric called the circularity index $(\kappa)$ to quantify the difference between the shape of the STA and STC subunits of the receptive field. The index $(\kappa)$ captures the extent to which the shape of receptive field subunit deviates from circular symmetry as follows:

$$
\begin{gathered}
\kappa=\frac{2}{\pi} \int_{0}^{2 \pi} 1-\frac{F_{\theta}}{F_{\theta, \max }} d \theta \\
F_{\theta}=\psi^{T} \cdot R(\psi, \theta)
\end{gathered}
$$

Here, $\mathrm{F}_{\theta}$ was calculated for $\theta=0, \pi / 2, \pi$, and $2 \pi$, with the maximum value, $\mathrm{F}_{\theta \text {, max }}$, whereas $\psi$ is the fit of the receptive field subunit and $\mathrm{R}$ is the rotation operator. $\kappa=0$ indicates perfect circular symmetry.

\section{LN models of the subthreshold neural response}

We built simple LN models of the subthreshold neural response using methods we developed earlier (Wang et al., 2007, 2011). The linear component of each model (the spatiotemporal receptive field) was estimated using linear regression: $k=\left(S^{T} S\right)^{-1} S^{T}$ r. Here $r$ is the continuous response, $\mathrm{S}$ is the stimulus, and $k$ is a matrix of size $\mathrm{m} \times n$ where $\mathrm{m}$ is the number of time bins and $n$ is the number of pixels in the receptive field. The nonlinearity was obtained by fitting a least square regression line to the relationship between the filter output and the intracellular response. The model was trained using 15 of 16 (15,360 frames) of the Gaussian noise sequence and tested with the remaining frames (Wang et al., 2011). Model performance was quantified by explained variance (Pearson's correlation coefficient, $r$ ).

\section{Histology and anatomical analysis}

After the animal was killed and perfused with 3\% PFA, the brain was removed. Coronal sections, $100 \mu \mathrm{m}$ thick, were processed using standard techniques (Hirsch et al., 1998). When possible, cells were classified as $X$, $Y$, or $W$ types based on their location, soma size, and dendritic morphology (Krahe et al., 2011) and reconstructed in three dimensions using commercial software Neurolucida (MBF Bioscience). The location of each labeled cell within its home LGN was matched to an equivalent site in a template LGN, allowing us to compare reconstructions across animals.

\section{Results}

Our longstanding interest is to understand how thalamic circuits integrate excitatory and inhibitory input to serve vision. 
a

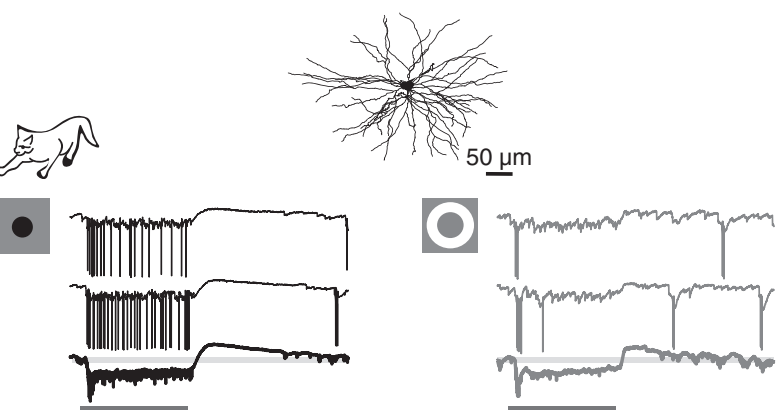

$\bullet$
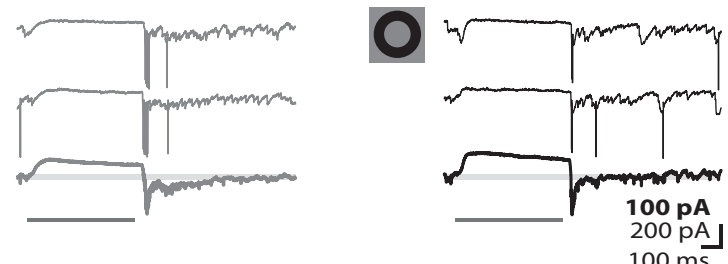

b

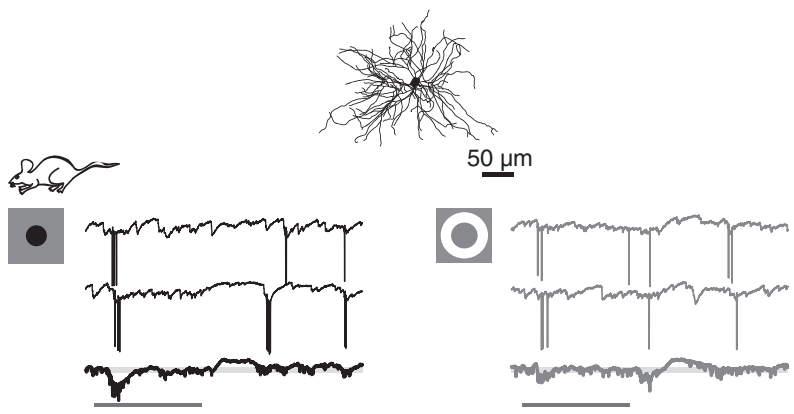

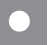
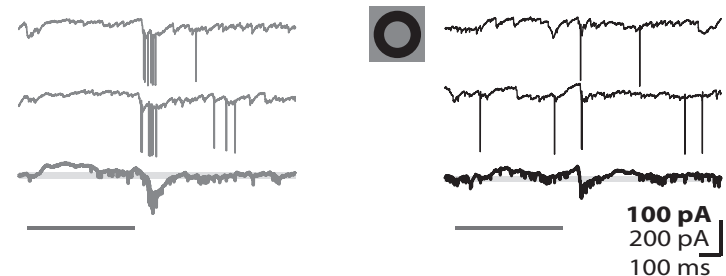

C
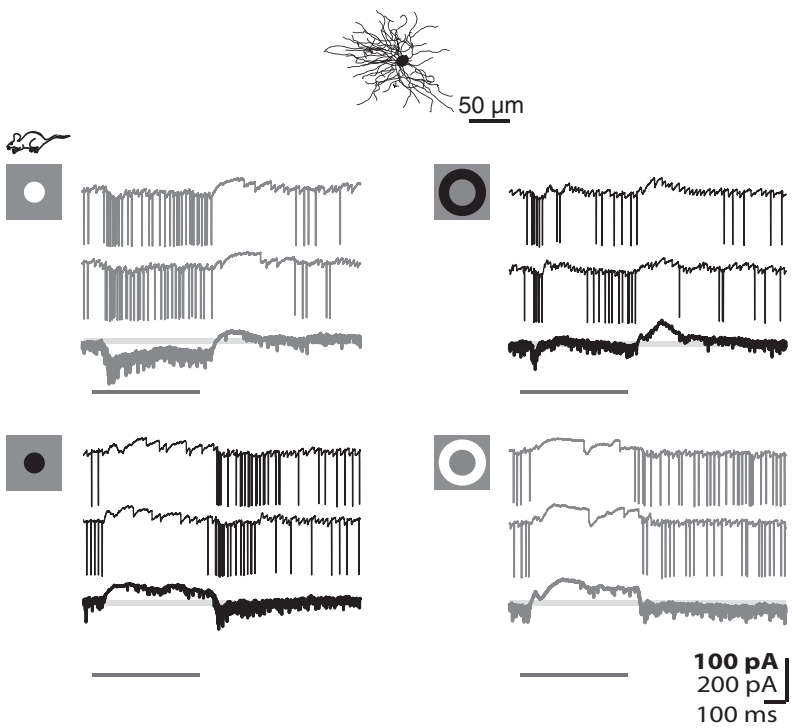

Figure 1. Push-pull organization of excitation and inhibition in the receptive fields of relay cells in carnivore and rodent. $\boldsymbol{a}$, Anatomical reconstruction of a feline Off-center shown above membrane currents evoked by dark and bright discs flashed in the center (left) and annuli flashed in the surround of the receptive field (right). Each panel represents two individual
Different species provide different advantages in exploring sensory function, with rodents offering increased ease and speed of experimentation, and the potential for genetic manipulation. By making whole-cell recordings with dye-filled electrodes in vivo, we explored the degree to which visually evoked patterns of excitation and inhibition in rodent resembled those in cat (the best studied animal model) and how they differed. Our sample included 109 cells in mouse and 22 cells in rat. For comparison, we also included data from 6 relay cells from cat, recorded in the course of earlier studies (Wang et al., 2007, 2011).

\section{Push-pull responses in cat versus rodent}

Most, if not all, relay cells in the cat have receptive fields built from concentric subregions that have the opposite preference for luminance contrast, On or Off (Wang et al., 2007). Furthermore, within each subregion, there is a push-pull arrangement of excitation and inhibition (Wang et al., 2007), as illustrated for a conventional Off-center relay cell (Fig. 1a). A dark disc confined to the center of the receptive field evoked an excitatory response (push) comprising EPSCs and spikes, as seen for two individual responses to the stimulus and the average (bolded) of all trials; stimulus duration is indicated by the dark gray bar (Fig. 1a, top left). Removal of the disc (a luminance increment, in effect) induced a hyperpolarizing current (pull). Accordingly, a bright disc flashed in same location elicited the opposite pattern of response, pull at stimulus onset and push at stimulus withdrawal (Fig. 1a, bottom left). Commensurate responses were recorded from the surround (Fig. 1a, right)

We repeated the same experiment in the rat (Fig. 1b) and mouse (Fig. 1c). On the whole, the push-pull responses of cat and rodent relay cells were comparable. The push was dominated by trains of EPSCs that continued during the stimulus period, and the pull by hyperpolarization. There were, however, subtle differences. First, the pull signal seemed weaker in rodent than cat. Stimuli that evoked the maximum pull routinely silenced retinal input in cat but failed to do so in rodent; compare the bottom panel of traces in Figure $1 a$ with those in Figure $1 b, c$. To quantify this difference across species, we detected retinogeniculate EPSCs (see Materials and Methods) from the intracellular signals of relay cells in cat and mouse while a suppressive stimulus was flashed in the receptive field center. Histograms of event rates (drawn in a unique color for each cell) show that retinogeniculate input during the pull is negligible in cat but persists at a slowed pace in rodent (Fig. 2b).

We sampled only the central region of the rat LGN and so cannot comment on whether or not there are reliable species differences between rodents. All remaining analyses of data from rodent were obtained from mouse as are all data reported in Table 1.

Many lines of evidence suggest that the push response is generated by retinogeniculate input (for a fuller explanation, see Wang et al., 2007). To determine whether the pull in rodent resulted from the withdrawal of excitation vs synaptic inhibition,

$\leftarrow$

responses to the stimulus, with averaged responses to multiple stimulus trials (bold traces) shown below at $2 \times$ gain. Icons at left represent stimuli. Black represents responses to dark stimuli. Gray represents responses to bright stimuli. Pale gray lines indicate baseline. Dark gray bars represent stimulus duration. $\boldsymbol{b}, \boldsymbol{c}$, Equivalent format as in $\boldsymbol{a}$ but for an Off-center cell in rat (b) and an On-center relay in mouse (c). 
a
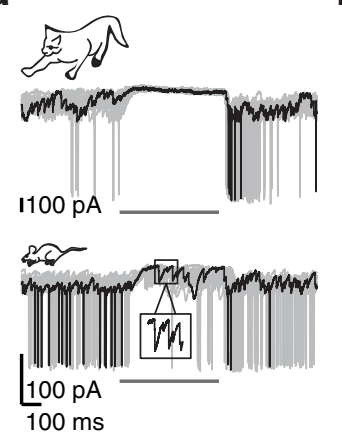

b
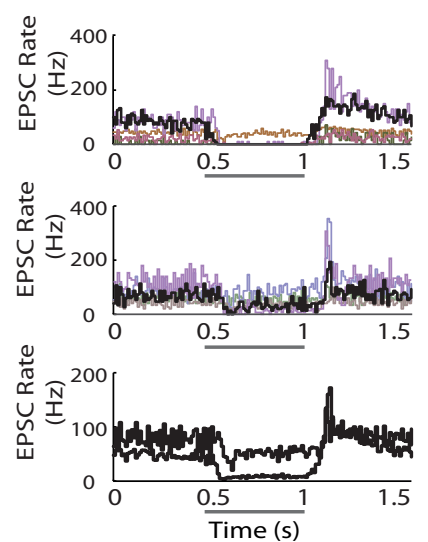

C
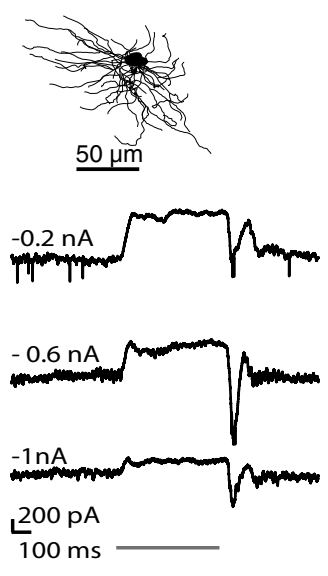

Figure 2. EPSC rates during the pull are higher in mouse than in cat. $\boldsymbol{a}$, Sample responses to discs of the nonpreferred contrast for relay cells in cat (top) and mouse (bottom); one sample trace is black and remaining traces are gray. Inset, EPSCs at expanded gain and timescale. $\boldsymbol{a}-\boldsymbol{c}$, Thin dark bar represents stimulus duration. $\boldsymbol{b}$, Histograms of EPSC rate before during and after the suppressive stimulus for 5 different relay cells in cat (top) and mouse (middle); results from thecells at left are shown in black and from the each remaining cell in a different color (bottom). Averaged histograms for all cells within each species are shown at $2 \times$ gain (event rates for mouse are always higher than those for cat). c, Anatomical reconstruction of an 0n-center relay cell in mouse (top) whose responses (bottom) to discs of the nonpreferred contrast recorded at progressively hyperpolarized levels are shown as averages of many stimulus trials.

Table 1. Different types of relay cells and their relative percentages in the mouse LGN ${ }^{a}$

\begin{tabular}{lcc}
\hline Cell type & $\begin{array}{l}\text { No. of cells recorded } \\
\text { intracellularly }\end{array}$ & Percentages \\
\hline On-center (push-pull) & 27 & 24.77 \\
Off-center (push-pull) & 20 & 18.35 \\
On-Off (non- orientation-selective/ & 19 & 17.43 \\
$\quad$ non-direction-selective) & & \\
Orientation-selective & 9 & 8.26 \\
Direction-selective & 6 & 5.50 \\
Local edge detector/W3-like & 5 & 4.59 \\
Suppressed by contrast & 8 & 7.34 \\
Unclassified & 15 & 13.76 \\
Total & 109 & 100 \\
\hline
\end{tabular}

${ }^{a}$ Relay cells were classified as On-center, Off-center, On-Off, W3-like, or suppressed-by-contrast-like based on responses to sparse noise, discs, and gratings. A subset of On-Off relay cells, whose responses to drifting gratings had OSI or DSI values $>0.33$ (Zhao et al., 2013), were further classified as orientation- or direction-selective. we recorded responses to a suppressive disc when the membrane was held at different levels of polarization (Fig. $2 c ; n=4$ cells). The pull grew smaller with progressive hyperpolarization, suggesting that it was generated by inhibition, as in cat (Wang et al., 2007) (an increase in response amplitude would have indicated withdrawal of excitatory drive). It is also possible that closure of NMDA channels contributed to the initial phase of the pull (Chen et al., 2002).

Predictive power of the spatiotemporal receptive field

For relay cells in cat and monkey, simple LN models based on the spatiotemporal receptive field predict neural response to novel visual stimuli reasonably well (Carandini et al., 2005). Thus, we asked whether this were true of murine relay cells whose receptive fields had a centersurround structure with push-pull. Traditional LN models are based on spike rate but can be adapted for intracellular signals (Wang et al., 2011). We recorded responses to full-field Gaussian noise (a sequence of checkerboards in which the luminance of each pixel is drawn from a Gaussian distribution; see Materials and Methods) and used reverse correlation (of the average membrane current to the stimulus) to generate the spatiotemporal receptive field. An example of the analysis for an On-center relay cell in cat (top) and mouse (bottom) is shown in Figure 3, the color code for On subregions is red and for Off subregions blue. The linear components of the model (the spatial and temporal receptive fields), the nonlinear function (used to map the output of the linear filter to response strength), and comparison of normalized neural and predicted responses are plotted from left to right (Fig. $3 a-d$ ). Model performance was similar between the mouse and cat (Fig. 3e). a
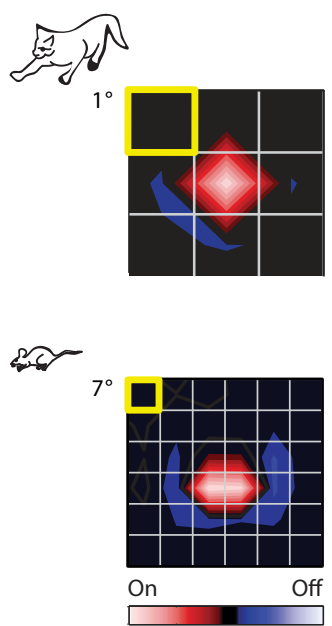

b
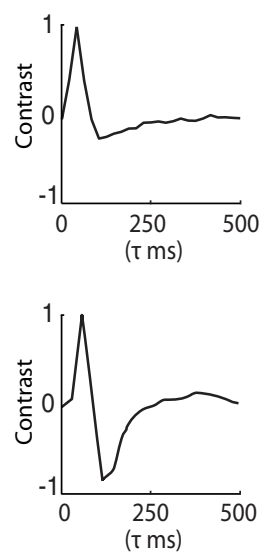

C
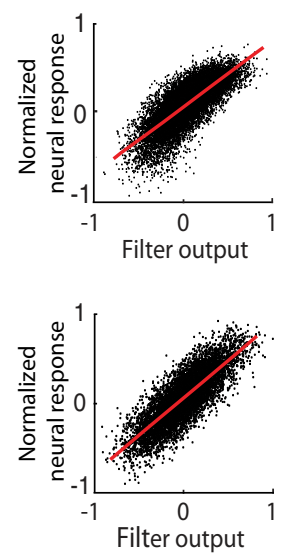

d
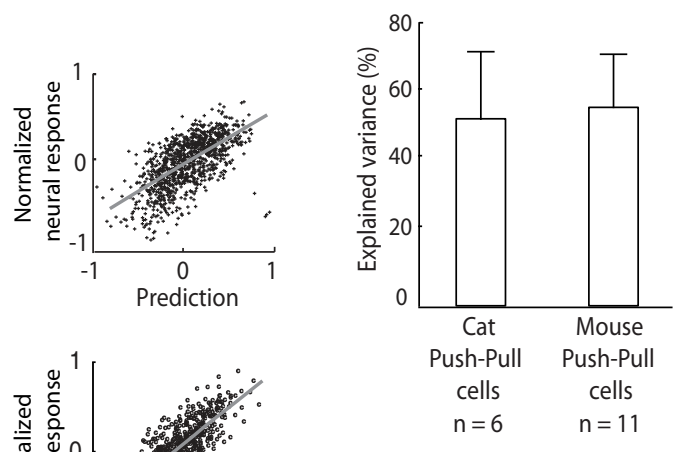

Figure 3. LN models for relay cells in cat and mouse. $\boldsymbol{a}, \boldsymbol{b}$, Spatial (left) and temporal (right) receptive fields of On-center relay cells in cat (top) and mouse (bottom) computed from intracellular responses to Gaussian noise. $c$, Scatter plots of the normalized membrane current against values obtained by convolving the stimulus with the spatiotemporal receptive field show how the nonlinear component of the model (red line) was fit. $\boldsymbol{d}$, Comparison of the normalized membrane and predicted responses. Gray line indicates the least squared fit. $\boldsymbol{e}$, Performance of the model quantified by explained variance. Error bars indicate SD. 
Scoring the spatial arrangement of push and pull in the receptive field

Although receptive fields with a center-surround structure are the vast majority in monkey and cat LGN (Hubel and Wiesel, 1961; Hubel and Wiesel, 1966) and retina, this is not the case for rodent. In mouse, the LGN receives substantial input from many types of ganglion cells (Huberman et al., 2008, 2009; Kim et al., 2008, 2010; Kay et al., 2011; Rivlin-Etzion et al., 2012), and extracellular recordings from murine relay cells have revealed commensurately sizeable populations of different types of receptive fields, such as On-Off (Piscopo et al., 2013; Zhao et al., 2013), and diverse response properties (Marshel et al., 2012; Piscopo et al., 2013; Scholl et al., 2013; Zhao et al., 2013).

To help compare the spatial arrangement of excitatory and suppressive input in conventional On and Off-center cells, such as those we have described in Figures 1-3, with that in other cell types in mouse, we mapped the synaptic structure of the receptive field with sparse noise, individually flashed bright and dark squares flashed in pseudorandom order along a $16 \times 16$ pixel stimulus grid (Jones et al., 1987). The resulting maps are displayed in two ways, as illustrated using the same mouse relay cell represented in Figures 1-3. First, the receptive field is shown as a contour plot made by subtracting responses to dark stimuli from those to bright stimuli (Fig. $4 a$, left). Second, the receptive field is displayed as an array of trace pairs (Fig. $4 a$, right). Here, averaged intracellular responses to bright (gray traces) and dark (black traces) squares are organized point by point along the stimulus grid; the center and surround are approximated by dashed contours. Robust push-pull currents dominate the center. Responses in the surround were weak because small squares are relatively ineffective compared with spatially coherent stimuli, such as annuli.

In past work on cortex, we quantified the presence of pushpull in receptive fields mapped with sparse noise by using a metric (Martinez et al., 2005) that we modified for this study and renamed the "E\I symmetry index." Positive values for this index indicate the presence of push-pull during the response, whereas negative scores indicate alternate arrangements of excitation and inhibition within the receptive field (Fig. 4b). Most cells (23 of 63) that were classified by eye as having push-pull responses to discs (horizontal hatch marks) had positive scores on the index, the exceptions being the few cells in which sparse noise evoked only weak pull (note, discs evoke stronger responses than sparse noise). Two On-Off cells also had positive scores in the index. In rat, 21 of 21 cells had a push-pull profile with positive scores (data not shown). The relay cells with negative scores ( $n=34$ of 63 cells) had different receptive field structures and response profiles, as we describe in the section below. We also measured the size of receptive fields. As a population, the average radius of the center subregion for push-pull cells was $11.4 \pm 6.81$ degrees.

\section{Diverse receptive field structures and response properties in rodent}

On-Off receptive fields

On-Off cells are driven by stimuli of either polarity presented to the same regions of visual space (Huberman et al., 2008, 2009; Kim et al., 2010; Rivlin-Etzion et al., 2012; Piscopo et al., 2013) rather than having spatially opponent On and Off subregions. For the cell illustrated in Figure $5 a$, introduction and withdrawal of bright and dark disks evoked modest but reliable depolarizations (trains of EPSCs and spikes), with the Off response the strongest in this case. Maps obtained with sparse noise show that the On and Off subregions had similar shapes (Fig. 5b); in this instance, the receptive field was elongated, but for other cells the fields were circular. Such On-Off re-

\section{a}

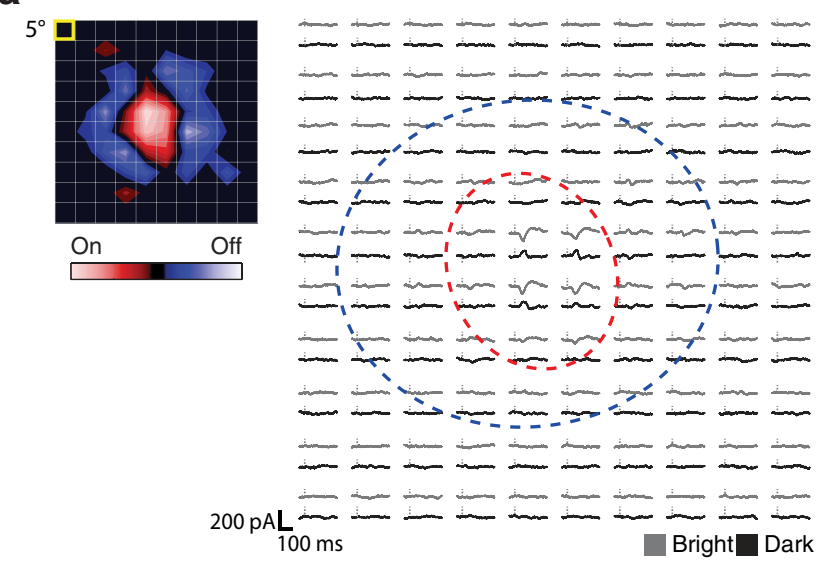

b

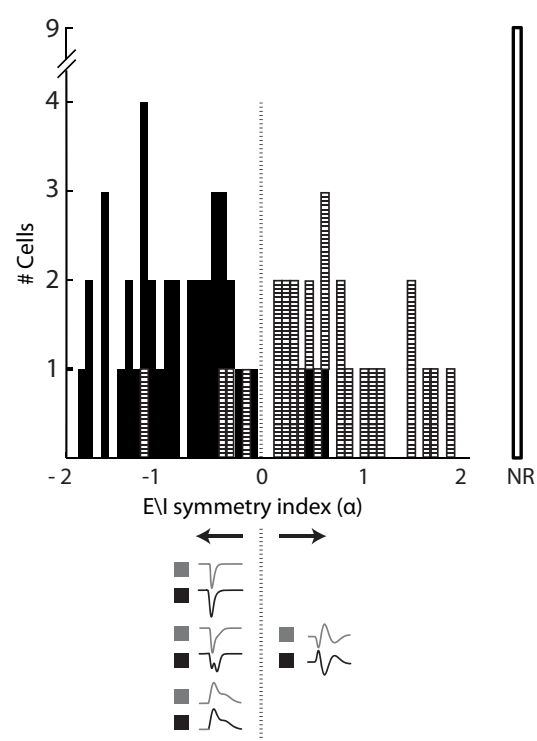

Figure 4. Pattern of excitation and inhibition in cells with push-pull and other types of responses. $\boldsymbol{a}$, Receptive field of an 0 -center relay cell mapped using sparse noise shown as a contour plot (left; yellow box represents stimulus size) and as an array of trace pairs (right) in which the averaged responses to bright (gray traces) and dark (black traces) to each stimulus are placed at corresponding positions in the stimulus grid. Vertical dashes indicate stimulus onset. Red dashed contour indicates the 0 n subregion. Blue dashed contour represents the Off subregion. $\boldsymbol{b}$, Histogram of the distribution of EV symmetry indices for relay cells mapped with sparse noise along with a graphical key at bottom. Hatched bins represent cells with push-pull responses. Filled bins represent those with other intracellular profiles. The unfilled bin labeled NR includes cells for which sparse noise did not drive responses.

sponses were common, representing $\sim 31.19 \%$ of our sample (Table 1). As we will discuss in later sections, a number of cells in this sample were selective for orientation or direction. The average receptive field radius of these cells was $8.18 \pm 3.8$ degrees, excluding neurons identified as belonging to the two distinct classes described in the following paragraphs.

\section{W3-like cells}

Historically, there is a special sort of On-Off retinal ganglion cell that is placed in its own category. These are called local edge detectors in rabbit (Levick, 1967; Zeck et al., 2005; van Wyk et al., 2006; Russell and Werblin, 2010) and their presumed analogs in mouse are named W3 cells (Zhang et al., 2012). W3 ganglion cells respond briefly and briskly to small stimuli but are silenced by large ones (Zhang et al., 2012). We have recorded from a class of relay cell in the LGN $(4.59 \%)$ with similar properties. W3-like 
a

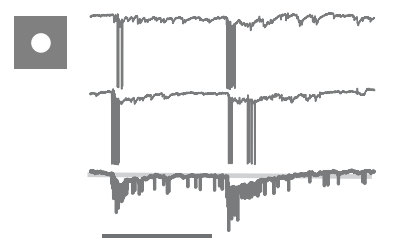

(

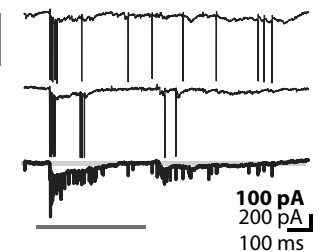

C
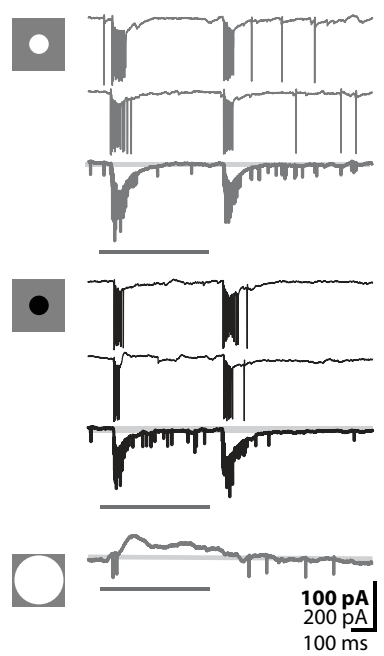

e

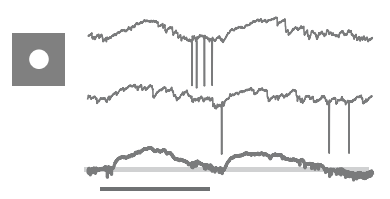

○

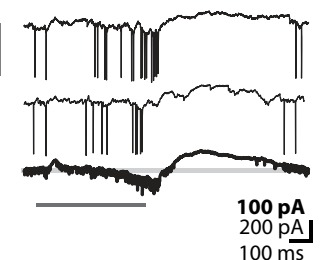

b
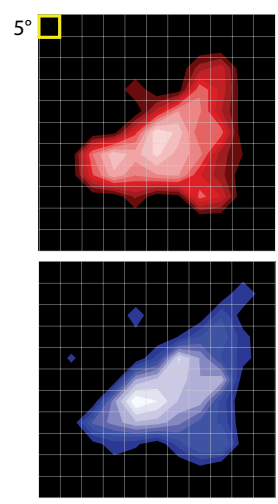

On Off

d

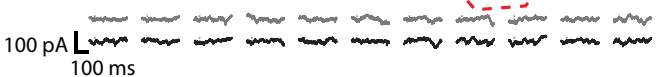
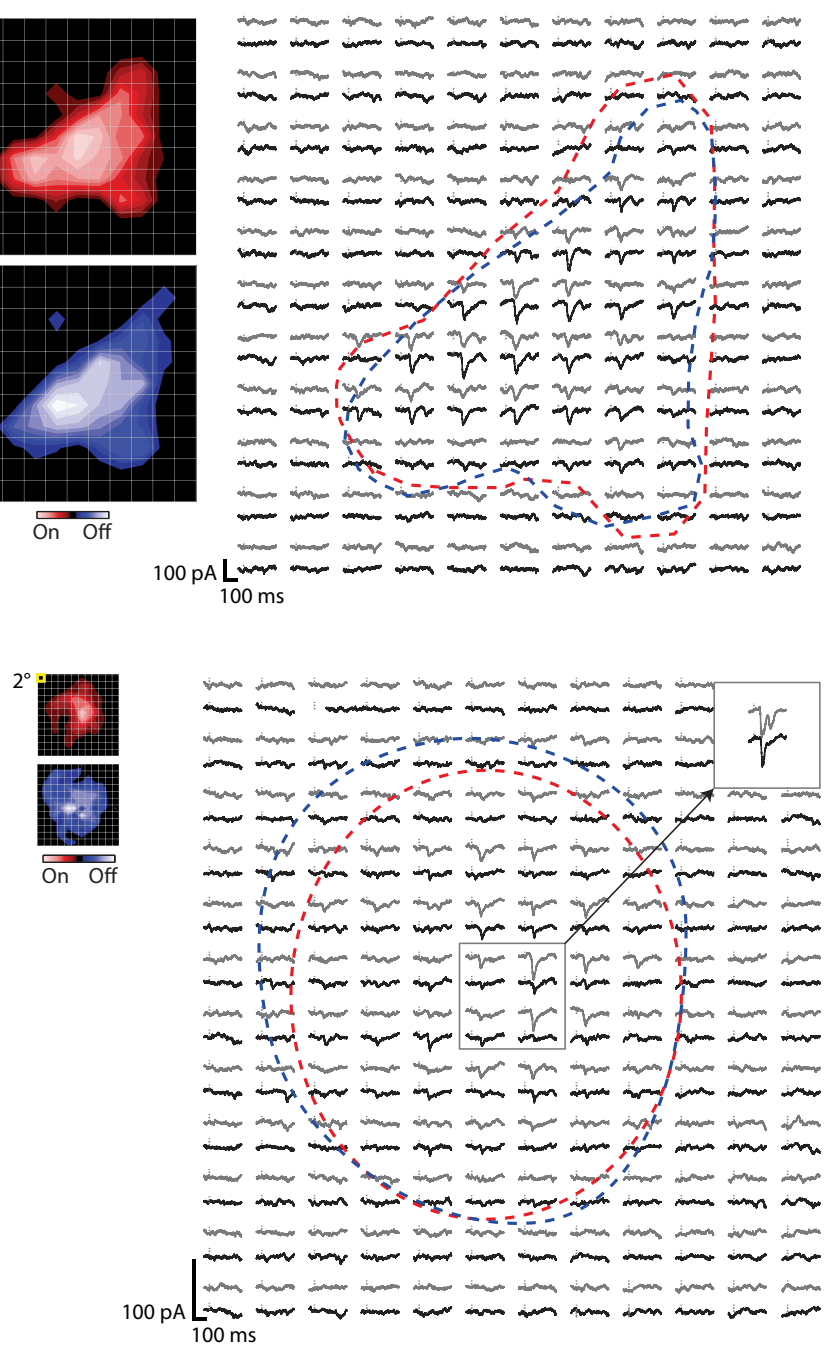

f
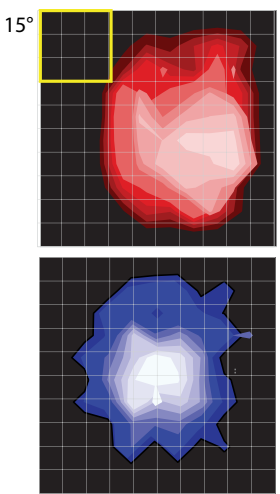

Inhibited Inhibited 100 by Bright by Dark

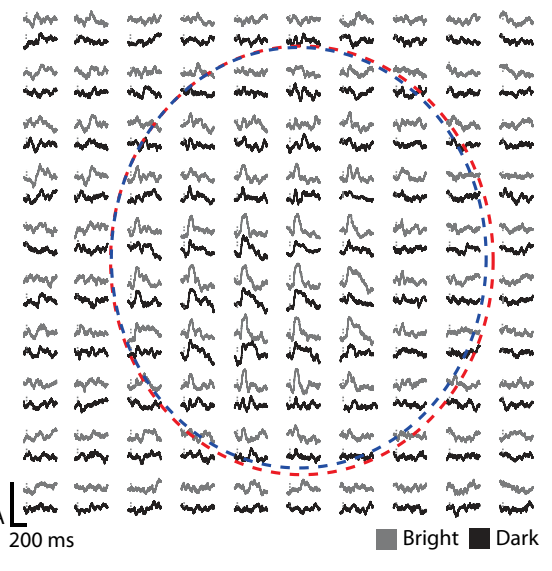

Figure 5. Response properties and receptive field structure of three different types of relay cells: On-0ff, W3-like, and suppressed-by-contrast-like. $\boldsymbol{a}$, Intracellular responses of an 0n-0ff cell to discs flashed within the center of the receptive field. Each panel represents two individual responses to the stimulus, with averaged responses to multiple stimulus trials (bold traces) shown below at $2 \times$ gain. Icons at left represent stimuli. Gray represents responses to bright stimuli. Black represents responses to dark stimuli. Pale gray lines indicate baseline. Dark gray bars represent stimulus duration. $\boldsymbol{b}$, Receptive field made with sparse noise for the same cell shown (left) as two contour plots made from responses to bright (top) or dark (bottom) spots (yellow box represents spot size), and (right) as an array of trace pairs in which the averaged responses to bright (gray traces) and dark (black traces) to each stimulus are placed at corresponding positions in the stimulus grid. Vertical dashes indicate stimulus onset. Red dashed contour indicates the 0 n subregion. Blue dashed contour indicates the Off subregion. $\boldsymbol{c}, \boldsymbol{d}$, Responses of a W3-like cell. c, Intracellular responses to flashed discs; conventions as in $\boldsymbol{a}$, with the addition of the averaged response to a large (100 degree) bright disc. $\boldsymbol{d}$, Receptive field maps for the W3-like cell; conventions as in $\boldsymbol{b}$, but with the addition of an inset (upper right) showing the response to 5 degree spot flashed within the center of the receptive field (gray box). $\boldsymbol{e}, \boldsymbol{f}$, Responses of a suppressed-by-contrast-like cell. $\boldsymbol{e}$, Intracellular responses to flashed discs; conventions as in $\boldsymbol{a}$. $\boldsymbol{f}$, Receptive field maps for the suppressed-by-contrast-like cell; conventions as in $\boldsymbol{b}$. 
relay cells fired a transient, high-frequency volley of spikes in response the presentation or withdrawal of optimally sized discs of either polarity (Fig. $5 c$ ). Firing rates were so fast that it was often impossible to visualize the underlying EPSCs. Large stimuli evoked strong suppression, as shown from responses to a large disc centered on the receptive field. For all but one of the W3-like cells in our sample, we were able calculate the extent that full-field versus focal stimuli suppressed spiking; the range was $72.5 \%-$ $94.3 \%(n=4)$. Furthermore, like their putative counterparts in retina, W3-like relay cells were neither orientation- nor direction-selective (data not shown). Synaptic currents evoked by very small spots $\left(2^{\circ}\right)$ (Fig. $5 d$ ) were inward and monophasic. However, the responses to somewhat larger spots $\left(5^{\circ}\right)$ had a more complicated shape (Fig. $5 d$, top right, inset). Bright spots elicited a "double bumped" response, whereas the response to dark spots was monophasic, recalling patterns observed in retina (Russell and Werblin, 2010). As a population, the receptive field size of these cells was the smallest, radius $5.5 \pm 1.38$ degrees. Our observations should be noted in light of the following caveat. W3 ganglion cells are selective for objection motion (Zhang et al., 2012), a property we did not evaluate.

Suppressed-by-contrast-like cells

Our sample includes a small (7.34\%) population of cells that resemble the murine analog (Tien et al., 2015) of those variously termed "suppressed-by-contrast" (Tailby et al., 2007; Piscopo et al., 2013; Tien et al., 2015) or uniformity detectors (Levick, 1967). For these cells, discs evoked a slow outward current that appeared to delay firing (Fig. 5e,f). In other words, EPSCs arrived early in the response but could not reach threshold until the suppression decayed (Fig. 5e). For this particular cell, the suppressive effect was more pronounced for luminance increments, but in other cases the reverse was true. It was necessary to use large stimuli to map the receptive fields, which were commensurately extensive (Fig. $5 f$ ); radius $14.13 \pm 3.99$ degrees. At the peak of the receptive field, suppressive epochs elicited at stimulus onset and at withdrawal seemed to blend but were easy to distinguish elsewhere. To give a sense of how these cells differed from others, we plotted values of a "bright-dark response polarity index," which scores the sign of the response to bright or dark stimuli at the peak of the receptive field (Fig. 6). Suppressed-by-contrast-like cells occupy the lower left quadrant of the plot, other On-Off cells fill the upper right, and cells with push-pull populate the upper left (Offcenter cells) and lower right (On-center cells) sectors.

\section{Tuning for stimulus orientation and direction sharpens in LGN}

So far, we have focused on the spatial distribution of excitation and inhibition in the receptive field. Here we explore how interactions between these two types of synaptic input help refine stimulus selectivity in the LGN. Specifically, we investigated retinothalamic transformations of orientation and direction selectivity by comparing tuning of retinogeniculate inputs and thalamic spikes for cells whose receptive fields we had previously mapped. Below we describe responses for oriented and for directional cells.

\section{Orientation selectivity}

The first step we took in analyzing orientation selectivity was to compare the tuning of retinogeniculate inputs with that of spikes. Rasters constructed from EPSCs and spikes are shown in Figure $7 a, b$ for a sample relay cell depicted in Figure $7 f$. Stimuli were sinusoidal gratings shown at various orientations at the preferred

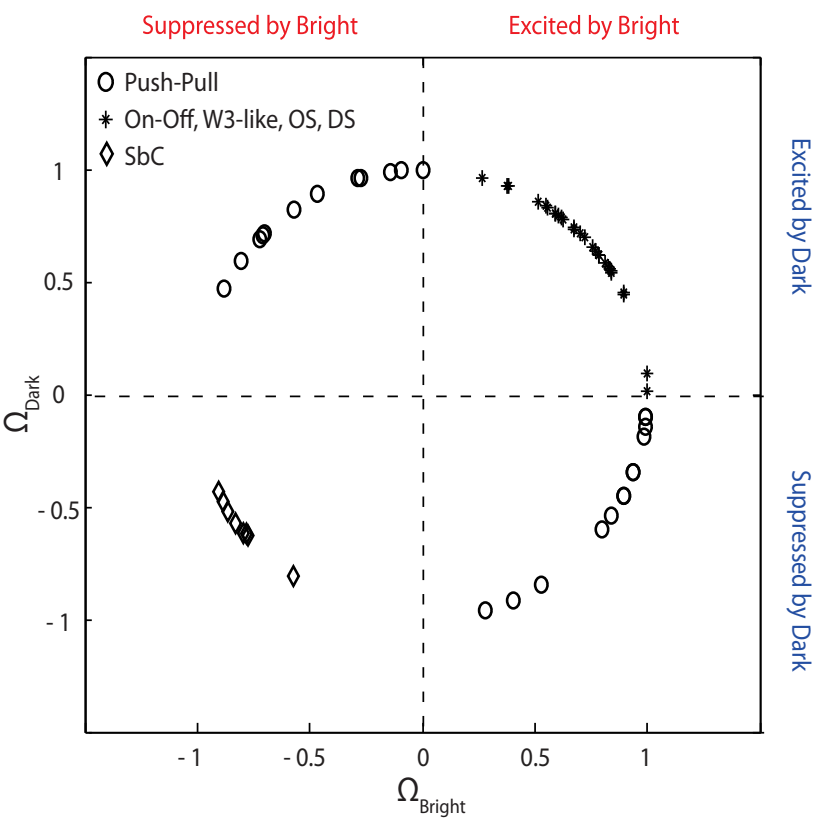

Figure 6. Suppressed-by-contrast-like cells are inhibited by bright and dark stimuli, unlike other $0 \mathrm{n}$-0ff cells and push-pull cells. Distribution of values for $a$ an index that reflects whether cells have excitatory, inhibitory, or the opposite responses to stimuli of both contrasts shows a separation of push-pull cells from 0n-Off cells and of suppressed-by-contrast-like-cells from other types of On-Off cells. SbC, Suppressed-by-contrast-like.

spatial and temporal frequency. Tuning, measured using the OSI (Piscopo et al., 2013) or the global OSI (Zhao et al., 2013) (see Materials and Methods), was lesser for EPSCs than spikes. Certainly, spike threshold must play a role in refining sensitivity. However, our intracellular recordings also implicate a role for inhibition, as seen in Figure 7c. At the preferred orientation and grating phase, EPSCs and spikes dominated the response, regardless of stimulus direction (Fig. $7 c$, top panels). By contrast, strong outward currents took precedence at suboptimal phases and suppressed residual EPSCs. At intermediate orientations, excitation diminished (Fig. $7 c$, middle panels). Orthogonally oriented gratings evoked hyperpolarizing currents across phases, although response strength adapted over time (Fig. $7 c$, bottom panels). Finally, we measured the total outward current evoked during the presentation of each orientated grating patch and found that it was untuned.

The motif of tuned excitation and untuned suppression held true for all cells tested, as depicted by polar plots in Figure $7 d$ for which the preferred orientation for all cells was rotated to align with the horizontal axis and as bar graphs in Figure 7e. Spikes were more sharply oriented than retinal inputs, whereas suppression was blind to stimulus angle $\left(\mathrm{OSI}_{\text {spikes }}=0.55 \pm 0.13\right.$, $\mathrm{OSI}_{\mathrm{EPSCs}}=0.27 \pm 0.03, \mathrm{OSI}_{\text {suppression }}=0.18 \pm 0.04, n=4$ cells; Fig. $7 d$ ). Thus, untuned suppression appears to sharpen selectivity in the LGN. The plots for spikes include data for which it was not possible to detect each EPSC with certainty $\left(\mathrm{OSI}_{\text {spikes }}=\right.$ $0.39 \pm 0.10, n=5)$. Last, for all the oriented cells whose receptive fields we mapped with discs or sparse noise (6 of 9), the receptive fields were On-Off.

\section{Direction selectivity}

A similar analysis is shown for a direction-selective cell (Fig. 8; conventions as in Fig. 7). Stimulus onset evoked a transient volley of spikes in all cases, but the remainder of the response varied as a function of stimulus direction. EPSC rates increased for grat- 
a
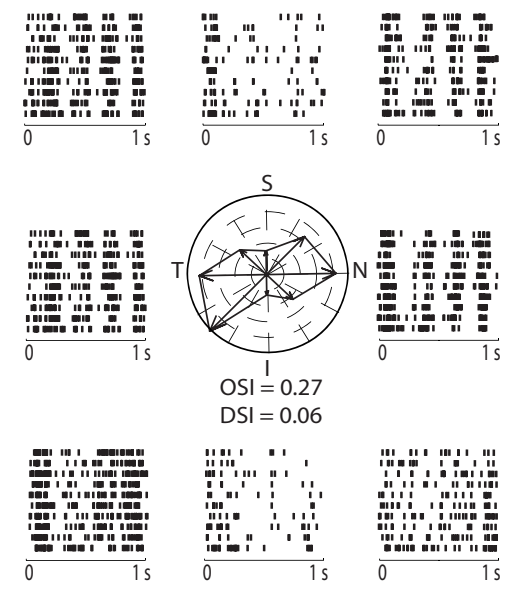

C
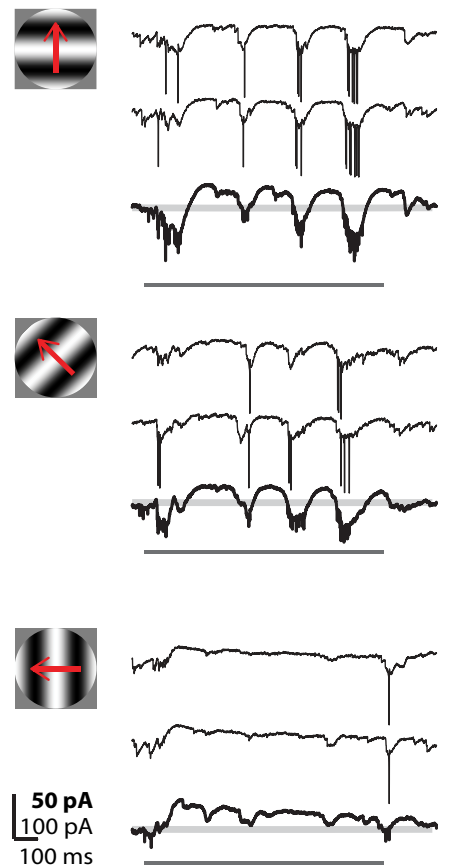

d

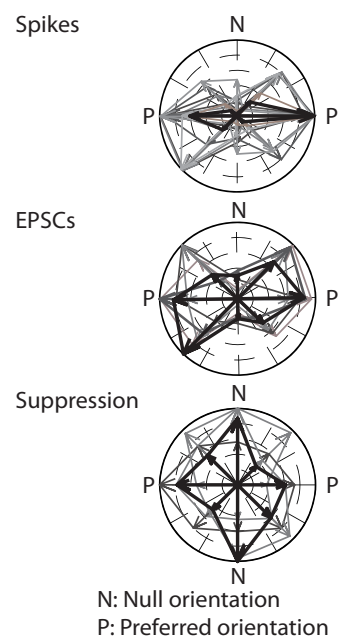

b
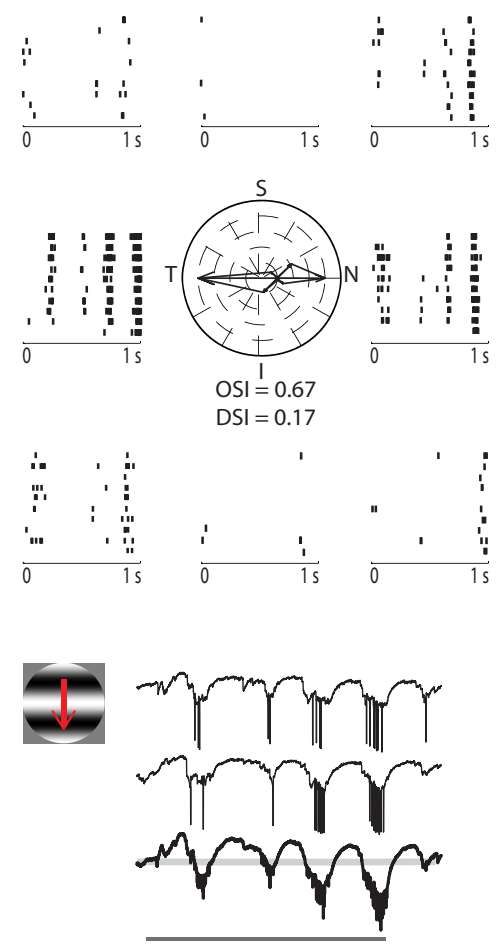

(3)

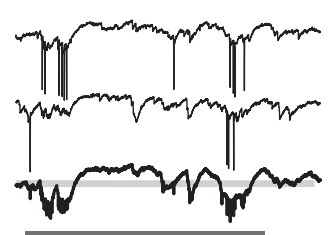

H
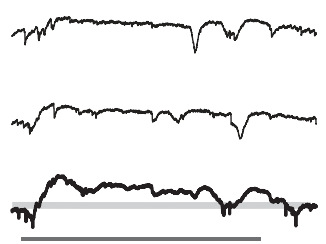

$\mathbf{e}$

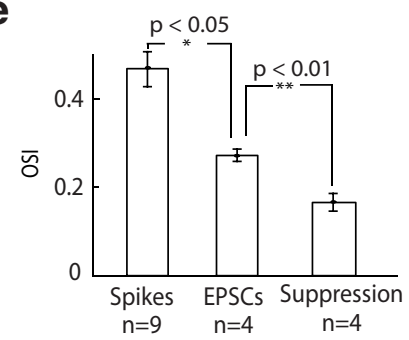

f

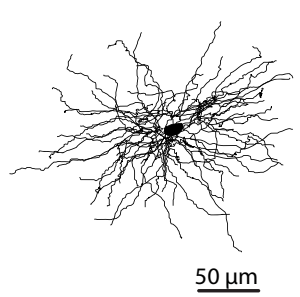

ings moving in the superior, nasal, and temporal directions (Fig. 8a), whereas suprathreshold responses were more selective, largely restricted to motion toward the superior and temporal visual field (Fig. 8b). Just as for orientation-selective cells, null stimuli evoked strong hyperpolarizing currents, as seen in the intracellular responses to drifting gratings (Fig. 8c). We did not construct tuning curves for suppression for these cells, however, because high firing rates maintained throughout some responses made it difficult to measure hyperpolarizing components of recordings (although our strong impression was that inhibition was broadly tuned). For four cells, DSI ${ }_{\text {spikes }}=$ $0.47 \pm 0.12$ and DSI $_{\mathrm{EPSCs}}=0.14 \pm 0.04$; for two additions cells for which EPSC detection was not possible, DSI $_{\text {spikes }}=0.45$ and 0.68 . The reconstruction of the cell is shown in Figure $8 d$ and tuning for the population is plotted in Figure $8 e$.

\section{Contributions of the receptive field to stimulus selectivity}

Although our results suggest that suppression sharpens tuning, it is also clear that the retinal inputs themselves are tuned. Thus, we designed several experiments to understand how different components of the receptive field might contribute to stimulus selectivity. First, we asked whether input from the center of the receptive field alone was sufficient to generate oriented responses. We found that cells whose responses to full-field gratings were selective for stimulus orientation lost their tuning when the stimulus was confined to the central region of the receptive field, as seen in the polar plots for EPSCs and spikes (Fig. 9a). This was true even though both the localized and the fullfield stimuli evoked robust responses.

$\leftarrow$

orientation; axes of the polar plots are labeled S (superior), I (inferior), T (temporal), and N (nasal). Each raster plot illustrates 10 repeats of the stimulus and is placed near the corresponding axis of the polar plot. $\boldsymbol{b}$, Equivalent plots for spikes. $\boldsymbol{c}$, Sample intracellular responses to gratings drifting in the preferred, oblique, and orthogonal orientations, as depicted by the stimulus icons. Responses to two individual trials of the stimulus are shown above the averaged responses to repeated presentations, bolded and displayed at $2 \times$ gain. Pale gray lines indicate baseline. Dark gray bars represent stimulus duration. $\boldsymbol{d}$, Polar plots of spikes, EPSCs, and suppression for orientation-selective cells. Data from each cell are shown in a different color, with the cell used for $\boldsymbol{a}$ - $\boldsymbol{c}$ in black. The tuning curve for each cell was rotated to align along the same (horizontal) axis. $\boldsymbol{e}$, Bar graph comparing the tuning of spikes, EPSCS, and suppression. Error bars indicate SD. Significance was assessed with a two-sample $t$ test. $f$, Anatomical reconstruction of the cell whose responses are illustrated in $\boldsymbol{a}-\boldsymbol{c}$.

Figure 7. Visually evoked membrane currents recorded from an orientation-selective 0 n-0ff relay cell. $\boldsymbol{a}$, Raster plots of EPSCS evoked by full-field sinusoidal gratings of different orientations drifting at $4 \mathrm{~Hz}$ surround a polar plot of EPSC rate at each 
a
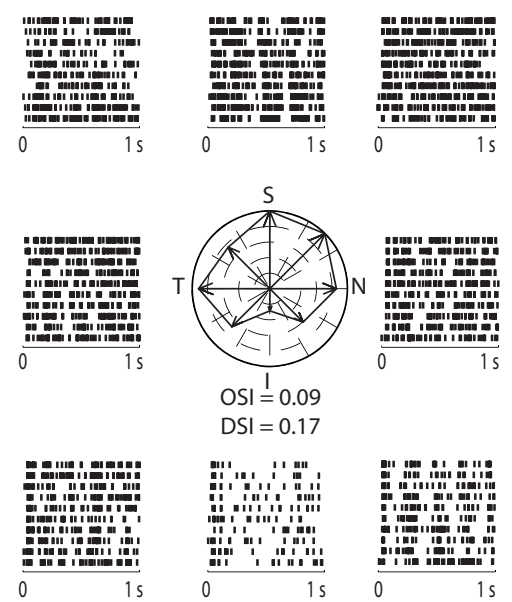

C
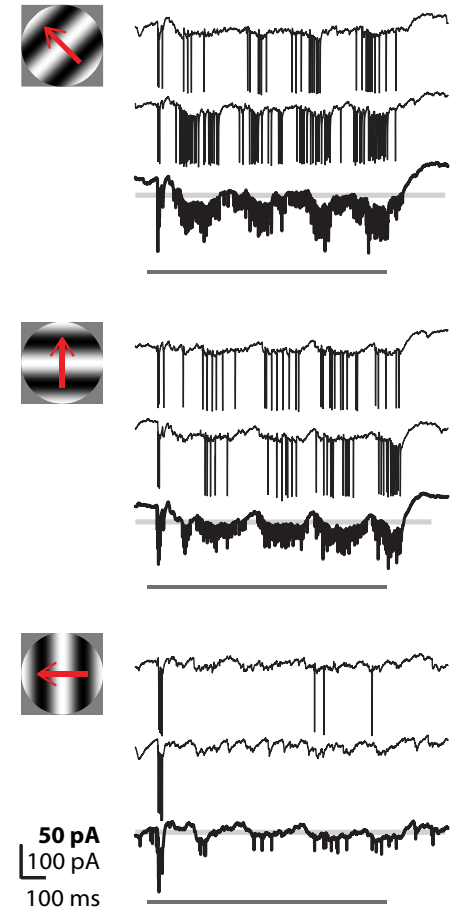

d

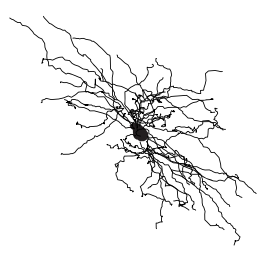

$\underline{50 \mu \mathrm{m}}$ b
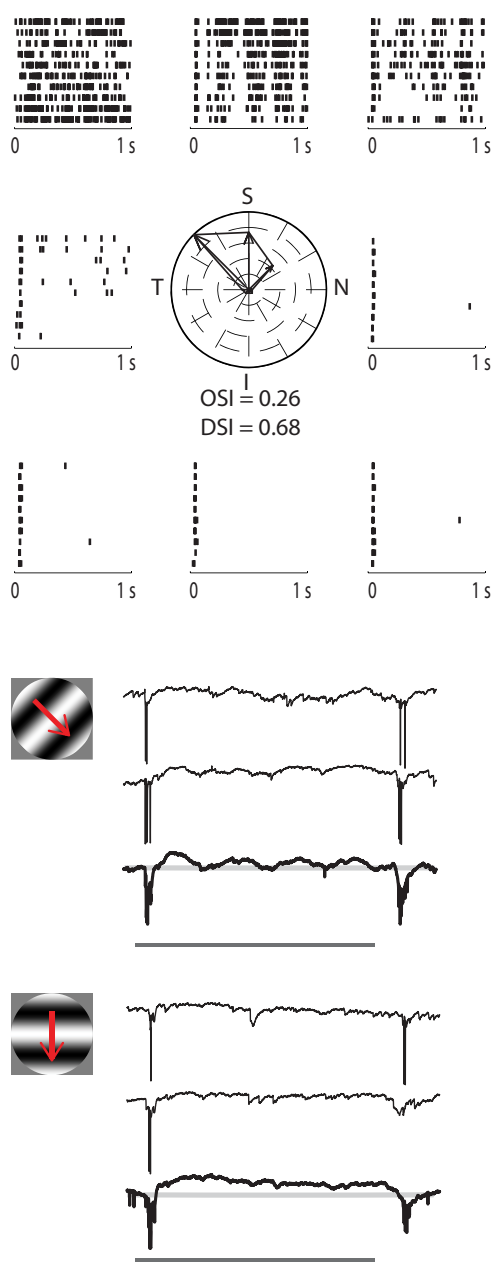

H

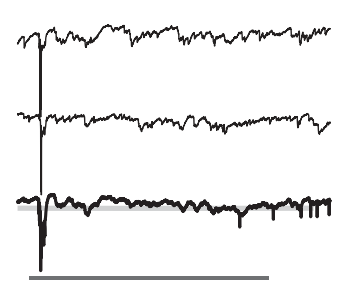

e

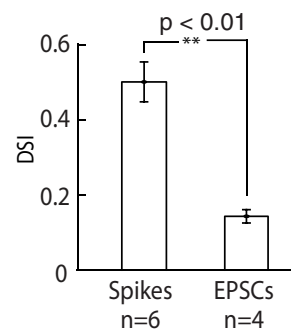

Figure 8. Visually evoked membrane currents recorded from a direction-selective On-0ff relay cell. $\boldsymbol{a}$, Raster plots of EPSCS evoked by full-field sinusoidal gratings of different orientations/directions of motion drifting at $4 \mathrm{~Hz}$ surround a polar plot of EPSC rate for each stimulus condition; axes of the polar plots are labeled S (superior), I (inferior), T (temporal), and N (nasal). Each raster plot illustrates 10 repeats of the stimulus and is placed near the corresponding axis of the polar plot. $\boldsymbol{b}$, Equivalent plots for spikes. c, Sample intracellular responses to gratings drifting in the preferred and suboptimal directions, as depicted by the stimulus icons. Responses to two individual trials of the stimulus are shown above the averaged responses to repeated presentations, bolded and displayed at $2 \times$ gain. Pale gray lines indicate baseline. Dark gray bars represent stimulus duration. $\boldsymbol{d}$, Anatomical reconstruction of the cell. $\boldsymbol{e}$, Bar graph comparing the tuning of spikes and EPSCs. Error bars indicate SD. Significance was assessed with a two-sample $t$ test.

Similar results for a direction-selective cell are shown in Figure $9 b$. The results depicted in this figure were obtained from the same two cells shown in Figures 7 and 8 ; similar profiles were seen for almost all oriented and direction-selective cells tested with small and large stimuli (Fig. $9 c)$. This observation suggests that the stimulus must cover a larger region of visual space to evoke tuned responses.

We further investigated contributions of different elements of the receptive field using reverse-correlation methods to analyze responses to Gaussian noise. Namely, we used event-triggered averages of the stimulus ensemble to recover firstorder subunits of the receptive field for EPSCs (ETAs) and spikes (STAs) and event-triggered covariance analysis to compute the second-order subunits (ETCs and STCs) of the receptive field (Schwartz et al., 2006; Vaingankar et al., 2012). The first-order component of the receptive field is the average of the stimulus frames that preceded EPSCs or spikes, whereas the second-order component reflects the covarying structure in the stimulus frames that preceded EPSCs or spikes (On and Off subregions that would cancel each other in the STA or ETA) (Schwartz et al., 2006).

We illustrate results for two On-Off relay cells: one tuned to the vertical (Fig. $10 a$ ) and the other to the horizontal orientation (Fig. 10b). The STAs and ETAs for both On-Off cells had approximately circular shapes and thus did not reflect stimulus orientation (Fig. 10a,b, leftmost contour plots). By contrast, the subunits recovered with event-triggered covariance analysis were oriented, as can be seen in the contour plots constructed from the data as well as Gabor fits (Fig. 10a,b, right); we used a new color code here because covariance analysis yields only the relative, but not the specific, contrast polarity of a given subregion. For comparison, we recovered the subunits of the receptive field of a direction-selective cell; neither the first- nor second-order subunits were oriented (Fig. 10c).

To quantify the difference in elongation between the STAs and STCs for oriented cells, we compared each subunit to a perfect circle using a circularity index (see Materials and Methods; Fig. 10d). Even though the STAs were somewhat asymmetric, they were always more circular than their corresponding STCs. If the structure of the receptive field contributes to orientation selectivity, then the axis of the oriented subunit should align with the neuron's preferred stimulus angle. Thus, 
a

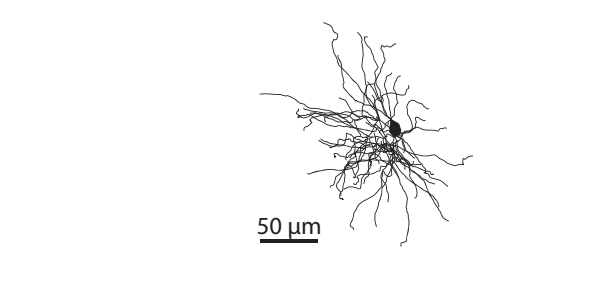

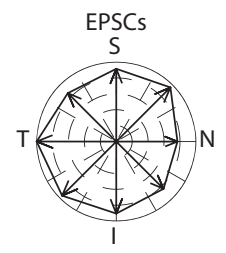

OSI $=0.03$

$\mathrm{DSI}=0.03$

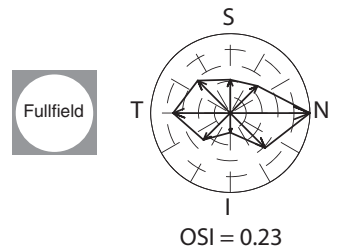

$\mathrm{DSI}=0.07$

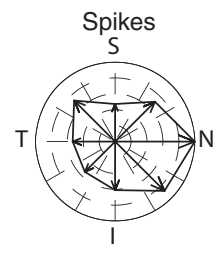

OSI $=0.10$

$\mathrm{DSI}=0.13$

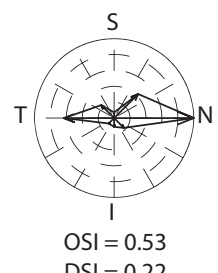

b

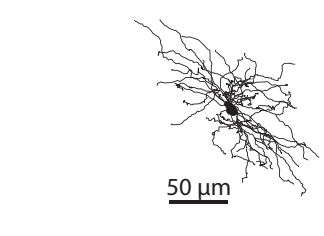

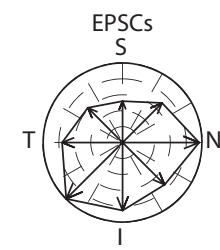

$\mathrm{OSI}=0.08$

$\mathrm{DSI}=0.10$

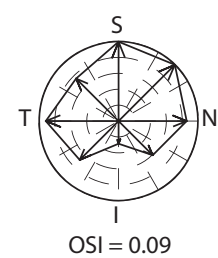

$\mathrm{DSI}=0.17$

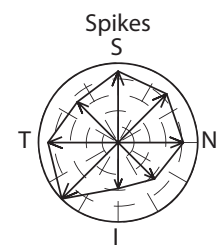

$\mathrm{OSI}=0.08$

$\mathrm{DSI}=0.05$

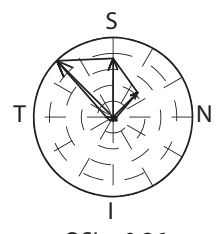

$\mathrm{OSI}=0.26$

$\mathrm{DSI}=0.68$
C

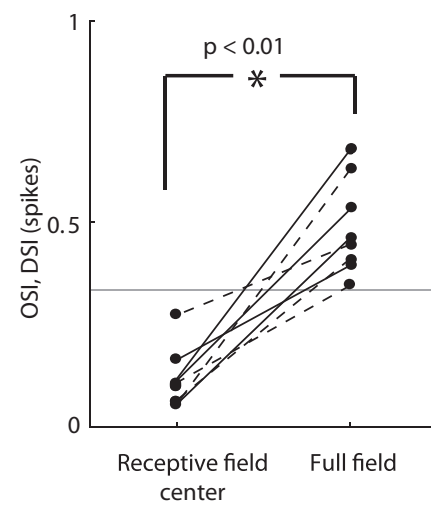

- - Direction selective cells _ Orientation selective cells

Figure 9. Dependence of orientation and direction selectivity on stimulus size. $\boldsymbol{a}$, Anatomical reconstruction of an orientation-selective 0n-0ff relay cell shown above polar plots constructed from EPSCS (left) and spikes (right) evoked by sinusoidal gratings of different orientations/directions of motion drifting at $4 \mathrm{~Hz}$; axes of the polar plots are labeled S (superior), I (inferior), $\mathrm{T}$ (temporal), and $\mathrm{N}$ (nasal). Responses evoked by a grating patch confined to the receptive field were not orientation-selective, whereas those evoked by full-field gratings were tuned. $\boldsymbol{b}$, Same as in $\boldsymbol{a}$, but illustrating the dependence of tuning on stimulus size for a direction-selective cell. c, Before-and-after plots of OSI and DSI computed for spikes as a function of stimulus size. Solid lines indicate orientationselective cells. Dotted lines indicate direction-selective cells. Gray line indicates DSI or OSI of 0.33. Significance was assessed with a two-sample $t$ test.

we plotted neural orientation preference against the axis of the fitted Gabor. The correlation coefficient was high $(r=0.88$; Fig. 10e), demonstrating a close relationship between orientation selectivity and the structure of the receptive field. The oriented subunits resembled simple receptive fields in cortex in that they comprised adjacent, elongated subregions of alternating sign (Hubel and Wiesel, 1962; Martinez et al., 2005; Niell and Stryker, 2008; Smith and Häusser, 2010; Bonin et al., 2011).

\section{Distribution of relay cell types in the LGN}

The dorsal division of the rodent LGN is divided into two main regions: a core and shell (Reese, 1988). Because we labeled many of the cells we recorded, it was possible to establish locations of diverse cell types in the nucleus (Fig. 11). Direction-selective cells were concentrated in the shell, as others have reported (Kim et al., 2008, 2010; Huberman et al., 2009; Kay et al., 2011; Rivlin-Etzion et al., 2012). Push-pull and oriented cells were distributed throughout the nucleus. On-Off (except for direction-selective cells) and suppressed-by-contrast-like cells were only found in the core, but our sample is too small to determine if these are exclusive to the region.

\section{Discussion}

Species differences emerge at each station of the visual pathway. Here we focused on the murine LGN and asked two main questions. First, are basic principles of synaptic integration used by higher species, such as cat, conserved in rodent LGN? Second, are there patterns of excitation and inhibition unique to rodent that contribute to stimulus selectivity? In cat, most relay cells have receptive fields with a center-surround shape and a push-pull organization of excitation and inhibition. Cells with this type of receptive field formed the largest single population in mouse LGN, indicating an important role in form vision. Still, the majority of cells had other types of receptive fields, including On-Off, W3-like, and suppressed-bycontrast-like. Subsets of On-Off cells were selective for stimulus direction or orientation; orientation preference could be predicted from the second-order, but not first-order subunits of the receptive field. Further, spikes were more narrowly tuned than retinal inputs, whereas suppression was untuned. Thus, thalamic inhibition seems to refine stimulus sensitivity in mouse. Also, there are $>30$ types of ganglion cells in mouse retina (Baden et al., 2016) and, potentially, substantial retinogeniculate convergence (Morgan et al., 2016; compare Chen et al., 2016). Thus, one might expect greater functional diversity in the murine LGN than we and others (Piscopo et al., 2013) report. Perhaps not all ganglion cells project to the LGN or, maybe, various types of retinal afferents play dominant versus auxiliary roles. Alternatively, there might be great variety in feature spaces (e.g., temporal) (Sincich et al., 2009; Wang et al., 2010) that have not yet been fully explored.

\section{Center-surround receptive fields and push-pull responses}

In cat, push-pull responses are found in the first three stations of the visual pathway: retina (Kuffler, 1953; Enroth-Cugell and Robson, 1984), LGN (Wang et al., 2007, 2011), and V1 (Hirsch et al., 1998). In mouse, push-pull responses are observed in retina (Pang et al., 2003; Werblin, 2010; Marco et al., 2013) but not cortex (Liu et al., 2009; Lien and Scanziani, 2013). To ask where this species difference might emerge, we determined the percentage of relay cells with push-pull and found that these form the largest population in the LGN. As in cat, these cells had receptive fields with a center-surround structure. Further, simple LN models predicted intracellular responses reasonably well and the pull relied on synaptic inhibition. 
a
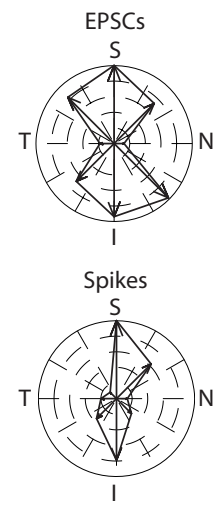

b
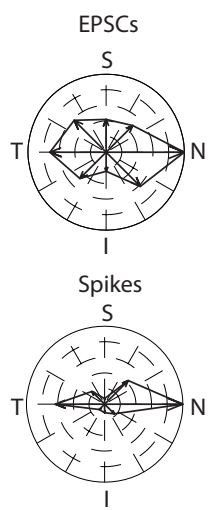

C

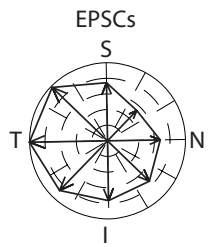

Spikes

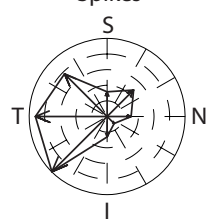

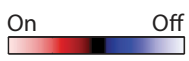
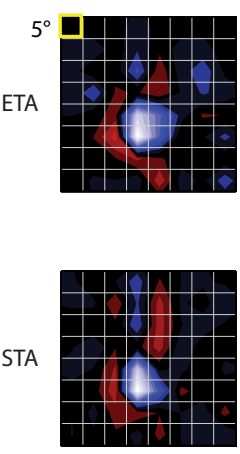

STC
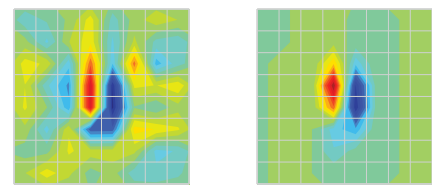

Fit
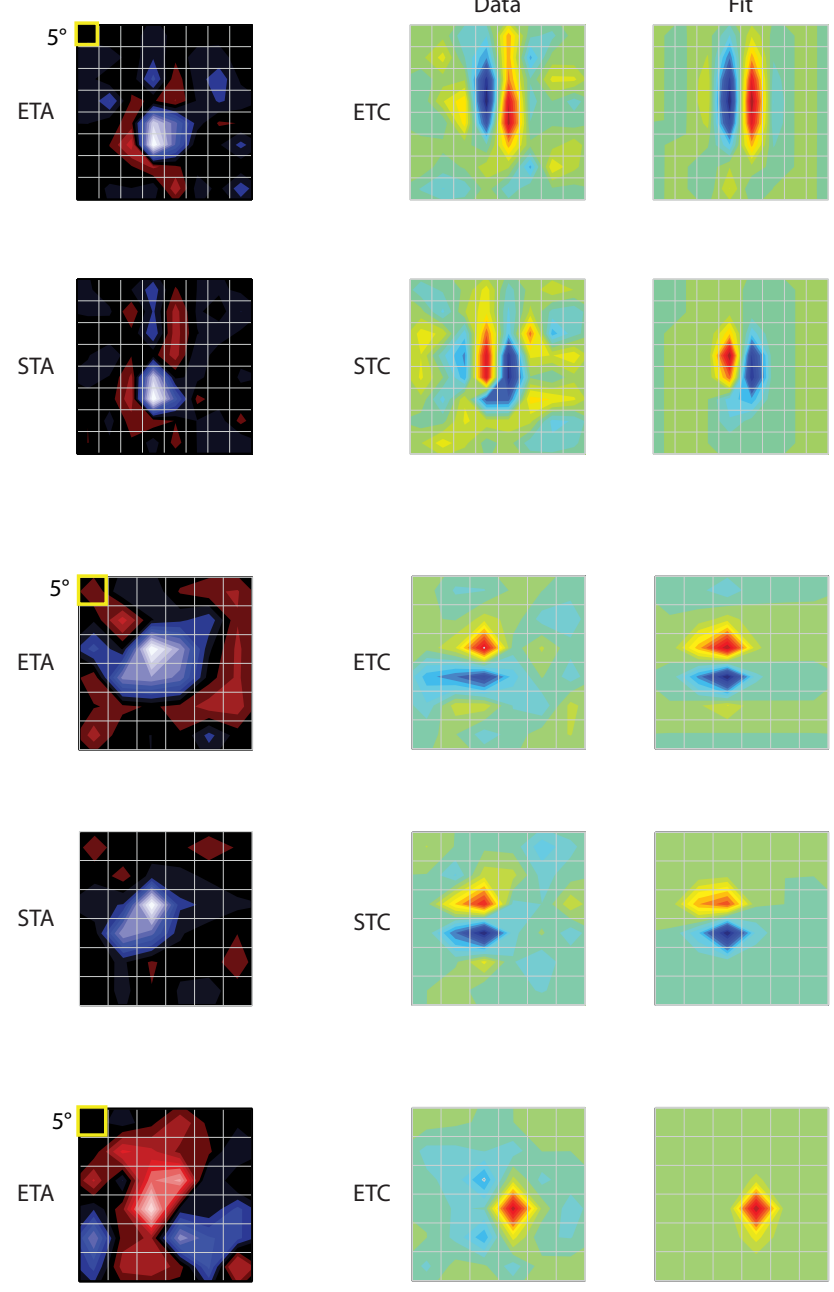

STA

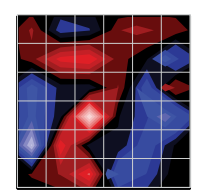

d

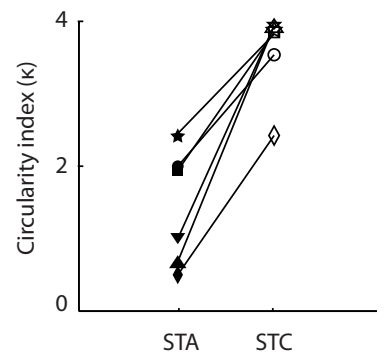

Open symbol: STC

Filled symbol: STA

e

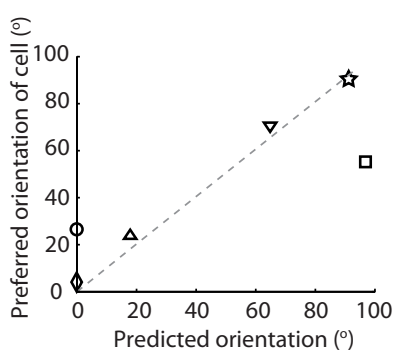

Figure 10. Receptive fields of orientation-selective cells have elongated higher-order subunits. $\boldsymbol{a}$, From left to right, Polar plot; first-order (ETA) subunit of the receptive field; second-order (ETC) subunit of the receptive field; and the fit of the ETC computed from EPSCS (top) and spikes (bottom) for an On-Off cell tuned to the vertical orientation. The color code for ETC/STC is different from ETA/STA because covariance analysis does not discriminate between the On and Off subregions. $\boldsymbol{b}$, Same as in $\boldsymbol{a}$, but for an $0 \mathrm{n}$-0ffcell tuned to the horizontal orientation. $\boldsymbol{c}$, Same as in $\boldsymbol{a}$, but for 0 n-0ff cell tuned for movement in the temporal direction. $\boldsymbol{d}$, Before and after plot of values of an index that compares the shape of the receptive field subunits with a perfect circle; the lower the value, the more circular the subunit. Index values for each cell are plotted with a unique symbol: open represents STC; filled represents STA. $\boldsymbol{e}$, Scatter plot of the preferred neural orientation against the orientation of the STC subunit, with symbol shapes as in $\boldsymbol{d}$. Dashed gray line indicates unity slope.

There were subtle species differences, however. The pull in murine relay cells was relatively weak, and some retinogeniculate EPSCs arrived during even the strongest inhibitory responses. The presence of EPSCs during the pull might reflect weak suppression in retina and/or convergent input from afferents with spatially offset or On-Off receptive fields.

Are circuits that generate push-pull responses in cat and rodent LGN similar? For the putative circuit in the cat (Wang et al., $2007,2011)$, the push is generated by ganglion cells that have the same sign (On or Off) as the postsynaptic thalamic neuron, whereas the pull is routed through thalamic interneurons whose receptive fields overlap that of their targets but have the opposite sign. This scheme assumes that the presynaptic interneurons have spatially localized receptive fields with a center-surround structure. Indeed, this is the case in cat, although interneurons have receptive fields larger than those of neighboring relay cells (Martinez et al., 2014).

Anatomical studies suggest that murine interneurons may have extensive receptive fields. Dendritic arbors of most inhibitory cells cross territories far wider than the extent of a single retinal axon (Dhande et al., 2011; Hong et al., 2014) to collect inputs from remote regions of visual space (Seabrook et al., 2013). Correspondingly, interneurons appear to pool more retinal afferents than relay cells do (Seabrook et al., 2013). Further, 


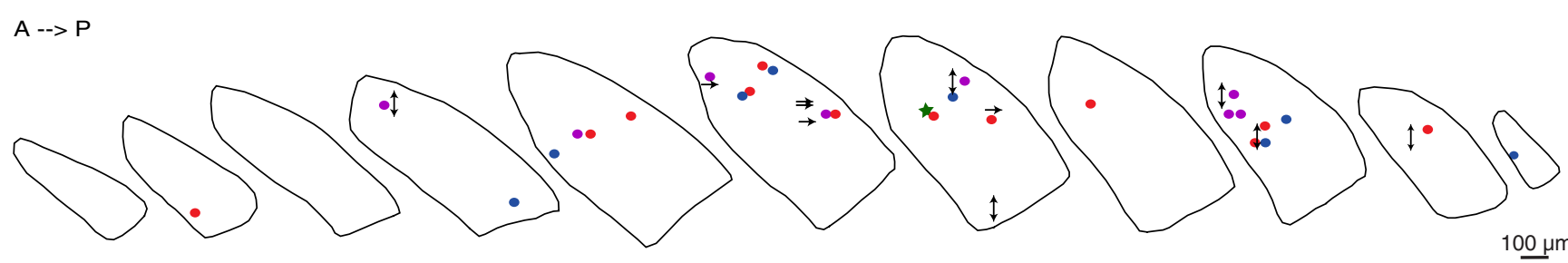

$10 \underline{\mu} \mu \mathrm{m}$
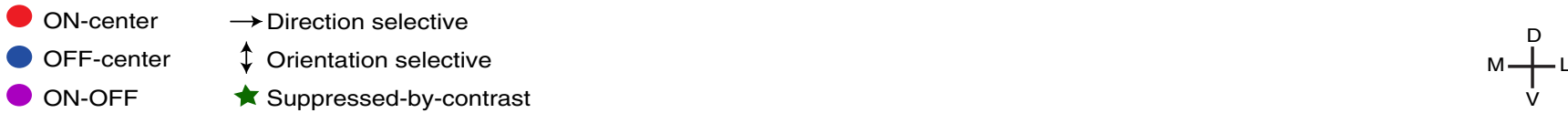

Figure 11. Anatomical distribution of different types of relay cells in mouse LGN. We labeled a subset of the cells whose physiological responses we characterized. The position of each of these cells is indicated within a series of coronal slices through a standardized LGN, using the following symbols for different physiological classes: filled red circle represents On-Center; filled blue circle represents $0 \mathrm{ff}$-Center; filled purple circle represents $0 \mathrm{n}$-0ff; single arrow indicates direction-selective; double arrow indicates orientation-selective; green star represents suppressed-by-contrast-like.

dendritic conductances propagate distal input throughout the somatodendritic membrane (Acuna-Goycolea et al., 2008; Casale and McCormick, 2011).

Still, it remains possible that some interneurons have receptive fields of the scale appropriate to provide the pull. For example, some might have small dendritic arbors and/or receive dominant input from ganglion cells with overlapping receptive fields. Alternatively, dendrites of interneurons might function as independent compartments that communicate via dendrodendritic synapses (Sherman, 2004) to operate at local spatial scales.

\section{On-Off suppression}

So far we have discussed cells with center-surround receptive fields and push-pull responses. Suppression also played an important role in neurons with overlapping On and Off subregions, such as W3-like and suppressed-by-contrast-like cells. Recalling putative counterparts in retina (Zhang et al., 2012), W3-like relay cells had small receptive fields and were excited by small spots but inhibited by large ones. Conversely, suppressed-by-contrast-like neurons had large receptive fields. For these cells, bright or dark spots evoked composite responses in which strong, lasting, inhibitory currents prevented retinal inputs from reaching threshold for long times.

Both W3-like and suppressed-by-contrast-like cells were inhibited by large uniform stimuli, bright or dark. What is the source of this suppression? Relay cells receive convergent input from multiple interneurons (Ziburkus et al., 2003). Perhaps the strength of the connections between interneurons and these relay cells is so weak that only expansive stimuli can recruit strong inhibitory drive.

\section{Receptive field structure in the form vision pathway}

Small receptive fields are usually associated with high spatial acuity and form vision. The $\beta$ cells in cat (or the parvo cells in monkey) have the smallest receptive fields (especially near central retina) and target the LGN (Berson, 2008). By contrast, the most numerous cell type in mouse retina, W3 cells (Zhang et al., 2012) (homologs of the rabbit's local edge detectors) (Levick, 1967; van Wyk et al., 2006; Russell and Werblin, 2010) have the smallest receptive fields. We found few W3-like responses in the LGN, suggesting a limited role in the classical form vision pathway.

Relay cells whose receptive fields have a center-surround structure with push-pull are the largest group in the LGN. Such receptive fields are similar to those of $\alpha$-sustained ganglion cells
(Marco et al., 2013; Bleckert et al., 2014), which target the LGN (Cruz-Martín et al., 2014). Alpha-sustained cells are most densely distributed in the retinal region that encodes the central visual field (Bleckert et al., 2014), similar to the situation for $\beta$ cells in carnivore and primate (for rabbit, see van Wyk et al., 2006). Viewing this information in the context of other species suggests that evolution favors receptive fields with a center-surround structure and a push-pull arrangement of excitation and inhibition for form vision in rodent, carnivore, and primate.

\section{Thalamic contributions to orientation- and direction-selective responses}

To ask whether thalamic mechanisms (in addition to thresholding) might refine stimulus selectivity in mouse, we compared the tuning of spikes, retinogeniculate EPSCs, and suppression. The tuning for spikes was sharper than that for EPSCs, whereas suppression was untuned, much as in mouse cortex (Niell and Stryker, 2008; Liu et al., 2009; Kerlin et al., 2010; Li et al., 2012). Thus, broadly tuned inhibition seems to enhance feature selectivity at both the thalamic and cortical stages of the murine geniculostriate pathway.

\section{The relationship between receptive field structure and orientation selectivity}

In cat, orientation selectivity emerges at the thalamocortical stage, where the geometry of the receptive field (or STA) predicts the preferred stimulus angle (Hubel and Wiesel, 1962; Martinez et al., 2002). This relationship between receptive field structure and orientation is also seen in rodent (Niell and Stryker, 2008; Liu et al., 2009; Smith and Häusser, 2010; Bonin et al., 2011; Lien and Scanziani, 2013) and primate (Hubel and Wiesel, 1968) cortex. By contrast, most oriented cells in the murine LGN have approximately circular receptive fields (STAs) (Zhao et al., 2013). To explore the basis of orientation tuning in mouse thalamus, we obtained the first-order (ETA, STA) and second-order (ETC, STC) subunits of the receptive field for oriented cells and found that the latter were oriented along the axis of the preferred stimulus angle.

These oriented subunits almost certainly derive from retina, perhaps with a contribution from orientation-selective Onganglion cells (Nath and Schwartz, 2016) rather than cortex. The EPSCs we detected had the shape and fast rates characteristic of retinal inputs (Wang et al., 2007; Koepsell et al., 2009). By contrast, cortical neurons fire at slow rates and unitary corticogeniculate inputs are usually too small to detect without pharma- 
cological aid (Granseth and Lindström, 2003). Some tectal inputs are oriented, but these only target the LGN shell (Bickford et al., 2015). Thus, convergent feedforward retinal input can, in principle, determine orientation preference.

It is also possible that orientation selectivity in the LGN results from the convergence of oppositely tuned, direction-selective ganglion cells (Marshel et al., 2012). Directional ganglion cells target the shell (Kim et al., 2008; Kay et al., 2011; Cruz-Martín et al., 2014), where many oriented cells reside (Marshel et al., 2012). We did not observe differences in the profiles of oriented cells in the core versus shell regions, however.

In conclusion, our intracellular analysis of the murine LGN has highlighted evolutionarily conserved principles of visual processing in thalamus and, at the same time, revealed synaptic mechanisms that may be unique to rodents and similar animals.

\section{References}

Acuna-Goycolea C, Brenowitz SD, Regehr WG (2008) Active dendritic conductances dynamically regulate GABA release from thalamic interneurons. Neuron 57:420-431. CrossRef Medline

Baden T, Berens P, Franke K, Román Rosón M, Bethge M, Euler T (2016) The functional diversity of retinal ganglion cells in the mouse. Nature 529:345-350. CrossRef Medline

Berson DM (2008) Retinal ganglion cell types and their central projections. In: The Senses (Masland R, Albright T, eds) pp 491-520. New York: Elsevier.

Bickford ME, Zhou N, Krahe TE, Govindaiah G, Guido W (2015) Retinal and tectal "driver-like" inputs converge in the shell of the mouse dorsal lateral geniculate nucleus. J Neurosci 35:10523-10534. CrossRef Medline

Bleckert A, Schwartz GW, Turner MH, Rieke F, Wong RO (2014) Visual space is represented by nonmatching topographies of distinct mouse retinal ganglion cell types. Curr Biol 24:310-315. CrossRef Medline

Bonin V, Histed MH, Yurgenson S, Reid RC (2011) Local diversity and fine-scale organization of receptive fields in mouse visual cortex. J Neurosci 31:18506-18521. CrossRef Medline

Carandini M, Demb JB, Mante V, Tolhurst DJ, Dan Y, Olshausen BA, Gallant JL, Rust NC (2005) Do we know what the early visual system does? J Neurosci 25:10577-10597. CrossRef Medline

Casale AE, McCormick DA (2011) Active action potential propagation but not initiation in thalamic interneuron dendrites. J Neurosci 31:1828918302. CrossRef Medline

Chang CC, Chih-Jen J (2011) LIBSVM: a library for support vector machines. ACM Trans Intelligent Syst Technol 2:27.21-27.27.

Chapman B, Zahs KR, Stryker MP (1991) Relation of cortical cell orientation selectivity to alignment of receptive fields of the geniculocortical afferents that arborize within a single orientation column in ferret visual cortex. J Neurosci 11:1347-1358. Medline

Chen C, Blitz DM, Regehr WG (2002) Contributions of receptor desensitization and saturation to plasticity at the retinogeniculate synapse. Neuron 33:779-788. CrossRef Medline

Chen C, Bickford ME, Hirsch JA (2016) Untangling the web between eye and brain. Cell 165:20-21. CrossRef Medline

Cheong SK, Tailby C, Solomon SG, Martin PR (2013) Cortical-like receptive fields in the lateral geniculate nucleus of marmoset monkeys. J Neurosci 33:6864-6876. CrossRef Medline

Cruz-Martín A, El-Danaf RN, Osakada F, Sriram B, Dhande OS, Nguyen PL, Callaway EM, Ghosh A, Huberman AD (2014) A dedicated circuit links direction-selective retinal ganglion cells to the primary visual cortex. Nature 507:358-361. CrossRef Medline

Dhande OS, Hua EW, Guh E, Yeh J, Bhatt S, Zhang Y, Ruthazer ES, Feller MB, Crair MC (2011) Development of single retinofugal axon arbors in normal and beta2 knock-out mice. J Neurosci 31:3384-3399. CrossRef Medline

Enroth-Cugell C, Robson JG (1984) Functional characteristics and diversity of cat retinal ganglion cells: basic characteristics and quantitative description. Invest Ophthalmol Vis Sci 25:250-267. Medline

Friedlander MJ, Lin CS, Stanford LR, Sherman SM (1981) Morphology of functionally identified neurons in lateral geniculate nucleus of the cat. J Neurophysiol 46:80-129. Medline

Girman S, Lund R (2010) Orientation-specific modulation of rat retinal ganglion cell responses and its dependence on relative orientations of the center and surround gratings. J Neurophysiol 104:2951-2962. CrossRef Medline

Granseth B, Lindström S (2003) Unitary EPSCs of corticogeniculate fibers in the rat dorsal lateral geniculate nucleus In vitro. J Neurophysiol 89: 2952-2960. CrossRef Medline

Grubb MS, Thompson ID (2003) Quantitative characterization of visual response properties in the mouse dorsal lateral geniculate nucleus. J Neurophysiol 90:3594-3607. CrossRef Medline

Hirsch JA, Martinez LM (2006) Circuits that build visual cortical receptive fields. Trends Neurosci 29:30-39. CrossRef Medline

Hirsch JA, Alonso JM, Reid RC, Martinez LM (1998) Synaptic integration in striate cortical simple cells. J Neurosci 18:9517-9528. Medline

Hirsch JA, Martinez LM, Pillai C, Alonso JM, Wang Q, Sommer FT (2003) Functionally distinct inhibitory neurons at the first stage of visual cortical processing. Nat Neurosci 6:1300-1308. CrossRef Medline

Hong YK, Park S, Litvina EY, Morales J, Sanes JR, Chen C (2014) Refinement of the retinogeniculate synapse by bouton clustering. Neuron 84 : 332-339. CrossRef Medline

Hubel DH, Wiesel TN (1961) Integrative action in the cat's lateral geniculate body. J Physiol 155:385-398. CrossRef Medline

Hubel DH, Wiesel TN (1962) Receptive fields, binocular interaction and functional architecture in the cat's visual cortex. J Physiol 160:106-154. CrossRef Medline

Hubel DH, Wiesel TN (1966) Effects of varying stimulus size and color on single lateral geniculate cells in Rhesus monkeys. Proc Natl Acad Sci U S A 55:1345-1346. CrossRef Medline

Hubel DH, Wiesel TN (1968) Receptive fields and functional architecture of monkey striate cortex. J Physiol 195:215-243. CrossRef Medline

Huberman AD, Manu M, Koch SM, Susman MW, Lutz AB, Ullian EM, Baccus SA, Barres BA (2008) Architecture and activity-mediated refinement of axonal projections from a mosaic of genetically identified retinal ganglion cells. Neuron 59:425-438. CrossRef Medline

Huberman AD, Wei W, Elstrott J, Stafford BK, Feller MB, Barres BA (2009) Genetic identification of an On-Off direction-selective retinal ganglion cell subtype reveals a layer-specific subcortical map of posterior motion. Neuron 62:327-334. CrossRef Medline

Jones JP, Stepnoski A, Palmer LA (1987) The two-dimensional spectral structure of simple receptive fields in cat striate cortex. J Neurophysiol 58:1212-1232. Medline

Kay JN, De la Huerta I, Kim IJ, Zhang Y, Yamagata M, Chu MW, Meister M, Sanes JR (2011) Retinal ganglion cells with distinct directional preferences differ in molecular identity, structure, and central projections. J Neurosci 31:7753-7762. CrossRef Medline

Kerlin AM, Andermann ML, Berezovskii VK, Reid RC (2010) Broadly tuned response properties of diverse inhibitory neuron subtypes in mouse visual cortex. Neuron 67:858-871. CrossRef Medline

Kim IJ, Zhang Y, Yamagata M, Meister M, Sanes JR (2008) Molecular identification of a retinal cell type that responds to upward motion. Nature 452:478-482. CrossRef Medline

Kim IJ, Zhang Y, Meister M, Sanes JR (2010) Laminar restriction of retinal ganglion cell dendrites and axons: subtype-specific developmental patterns revealed with transgenic markers. J Neurosci 30:14521462. CrossRef Medline

Koepsell K, Wang X, Vaingankar V, Wei Y, Wang Q, Rathbun DL, Usrey WM, Hirsch J, Sommer FT (2009) Retinal oscillations carry visual information to cortex. Front Sys Neurosci 3:4. CrossRef Medline

Krahe TE, El-Danaf RN, Dilger EK, Henderson SC, Guido W (2011) Morphologically distinct classes of relay cells exhibit regional preferences in the dorsal lateral geniculate nucleus of the mouse. J Neurosci 31:1743717448. CrossRef Medline

Kuffler SW (1953) Discharge patterns and functional organization of the mammalian retina. J Neurophysiol 16:37-68. Medline

Lam YW, Cox CL, Varela C, Sherman SM (2005) Morphological correlates of triadic circuitry in the lateral geniculate nucleus of cats and rats. J Neurophysiol 93:748-757. CrossRef Medline

Levick WR (1967) Receptive fields and trigger features of ganglion cells in the visual streak of the rabbits retina. J Physiol 188:285-307. CrossRef Medline

Li YT, Ma WP, Li LY, Ibrahim LA, Wang SZ, Tao HW (2012) Broadening of inhibitory tuning underlies contrast-dependent sharpening of orienta- 
tion selectivity in mouse visual cortex. J Neurosci 32:16466-16477. CrossRef Medline

Lien AD, Scanziani M (2013) Tuned thalamic excitation is amplified by visual cortical circuits. Nat Neurosci 16:1315-1323. CrossRef Medline

Liu BH, Li P, Sun YJ, Li YT, Zhang LI, Tao HW (2009) Intervening inhibition underlies simple-cell receptive field structure in visual cortex. Nat Neurosci Rev 13:89-96. CrossRef Medline

Marco SD, Protti DA, Solomon SG (2013) Excitatory and inhibitory contributions to receptive fields of alpha-like retinal ganglion cells in mouse. J Neurophysiol 110:1426-1440. CrossRef Medline

Marshel JH, Kaye AP, Nauhaus I, Callaway EM (2012) Anterior-posterior direction opponency in the superficial mouse lateral geniculate nucleus. Neuron 76:713-720. CrossRef Medline

Martinez LM, Alonso JM, Reid RC, Hirsch JA (2002) Laminar processing of stimulus orientation in cat visual cortex. J Physiol 540:321-333. CrossRef Medline

Martinez LM, Wang Q, Reid RC, Pillai C, Alonso JM, Sommer FT, Hirsch JA (2005) Receptive field structure varies with layer in the primary visual cortex. Nat Neurosci 8:372-379. CrossRef Medline

Martinez LM, Molano-Mazón M, Wang X, Sommer FT, Hirsch JA (2014) Statistical wiring of thalamic receptive fields optimizes spatial sampling of the retinal image. Neuron 81:943-956. CrossRef Medline

Montero VM, Brugge JF, Beitel RE (1968) Relation of the visual field to the lateral geniculate body of the albino rat. J Neurophysiol 31:221-236. Medline

Morgan JL, Berger DR, Wetzel AW, Lichtman JW (2016) The fuzzy logic of network connectivity in mouse visual thalamus. Cell 165:192-206. CrossRef Medline

Nath A, Schwartz GW (2016) Cardinal orientation selectivity is represented by two distinct ganglion cell types in mouse retina. J Neurosci 36:32083221. CrossRef Medline

Niell CM, Stryker MP (2008) Highly selective receptive fields in mouse visual cortex. J Neurosci 28:7520-7536. CrossRef Medline

Pang JJ, Gao F, Wu SM (2003) Light-evoked excitatory and inhibitory synaptic inputs to ON and OFF alpha ganglion cells in the mouse retina. J Neurosci 23:6063-6073. Medline

Piscopo DM, El-Danaf RN, Huberman AD, Niell CM (2013) Diverse visual features encoded in mouse lateral geniculate nucleus. J Neurosci 33:46424656. CrossRef Medline

Reese BE (1988) 'Hidden lamination' in the dorsal lateral geniculate nucleus: the functional organization of this thalamic region in the rat. Brain Res 472:119-137. Medline

Rivlin-Etzion M, Wei W, Feller MB (2012) Visual stimulation reverses the directional preference of direction-selective retinal ganglion cells. Neuron 76:518-525. CrossRef Medline

Roth MM, Dahmen JC, Muir DR, Imhof F, Martini FJ, Hofer SB (2016) Thalamic nuclei convey diverse contextual information to layer 1 of visual cortex. Nat Neurosci 19:299-307. CrossRef Medline

Russell TL, Werblin FS (2010) Retinal synaptic pathways underlying the response of the rabbit local edge detector. J Neurophysiol 103:2757-2769. CrossRef Medline

Scholl B, Tan AY, Corey J, Priebe NJ (2013) Emergence of orientation selectivity in the mammalian visual pathway. J Neurosci 33:10616-10624. CrossRef Medline

Schwartz O, Pillow JW, Rust NC, Simoncelli EP (2006) Spike-triggered neural characterization. J Vis 6:484-507. CrossRef Medline

Seabrook TA, Krahe TE, Govindaiah G, Guido W (2013) Interneurons in the mouse visual thalamus maintain a high degree of retinal convergence throughout postnatal development. Neural Dev 8:24. CrossRef Medline

Sherman SM (2004) Interneurons and triadic circuitry of the thalamus. Trends Neurosci 27:670-675. CrossRef Medline

Simoncelli EP, Pillow J, Paninski L, Schwartz O (2004) Characterization of neural responses with stochastic stimuli. In: The cognitive neurosciences,
Vol III (Gazzaniga M, ed), pp 327-338. Cambridge, MA: Massachusetts Institute of Technology.

Sincich LC, Horton JC, Sharpee TO (2009) Preserving information in neural transmission. J Neurosci 29:6207-6216. CrossRef Medline

Smith SL, Häusser M (2010) Parallel processing of visual space by neighboring neurons in mouse visual cortex. Nat Neurosci 13:1144-1149. CrossRef Medline

Sutton JK, Brunso-Bechtold JK (1991) A Golgi study of dendritic development in the dorsal lateral geniculate nucleus of normal ferrets. J Comp Neurol 309:71-85. CrossRef Medline

Tailby C, Solomon SG, Dhruv NT, Majaj NJ, Sokol SH, Lennie P (2007) A new code for contrast in the primate visual pathway. J Neurosci 27:39043909. CrossRef Medline

Tang J, Ardila Jimenez SC, Chakraborty S, Schultz SR (2016) Visual receptive field properties of neurons in the mouse lateral geniculate nucleus. PLoS One 11:e0146017. CrossRef Medline

Tien NW, Pearson JT, Heller CR, Demas J, Kerschensteiner D (2015) Genetically identified suppressed-by-contrast retinal ganglion cells reliably signal self-generated visual stimuli. J Neurosci 35:10815-10820. CrossRef Medline

Usrey WM, Alitto HJ (2015) Visual functions of the thalamus. Annu Rev Vis Sci 1:351-371. CrossRef

Vaingankar V, Soto-Sanchez C, Wang X, Sommer FT, Hirsch JA (2012) Neurons in the thalamic reticular nucleus are selective for diverse and complex visual features. Front Integr Neurosci 6:118. CrossRef Medline

van Wyk M, Taylor WR, Vaney DI (2006) Local edge detectors: a substrate for fine spatial vision at low temporal frequencies in rabbit retina. J Neurosci 26:13250-13263. CrossRef Medline

Wang X, Wei Y, Vaingankar V, Wang Q, Koepsell K, Sommer FT, Hirsch JA (2007) Feedforward excitation and inhibition evoke dual modes of firing in the cat's visual thalamus during naturalistic viewing. Neuron 55:465-478. CrossRef Medline

Wang X, Hirsch JA, Sommer FT (2010) Recoding of sensory information across the retinothalamic synapse. J Neurosci 30:13567-13577. CrossRef Medline

Wang X, Vaingankar V, Soto Sanchez C, Sommer FT, Hirsch JA (2011) Thalamic interneurons and relay cells use complementary synaptic mechanisms for visual processing. Nat Neurosci 14:224-231. CrossRef Medline

Weng S, Sun W, He S (2005) Identification of ON-OFF direction-selective ganglion cells in the mouse retina. J Physiol 562:915-923. CrossRef Medline

Werblin FS (2010) Six different roles for crossover inhibition in the retina: correcting the nonlinearities of synaptic transmission. Vis Neurosci 27: 1-8. CrossRef Medline

Williams SR, Turner JP, Anderson CM, Crunelli V (1996) Electrophysiological and morphological properties of interneurones in the rat dorsal lateral geniculate nucleus in vitro. J Physiol 490:129-147. CrossRef Medline

Zeck GM, Xiao Q, Masland RH (2005) The spatial filtering properties of local edge detectors and brisk-sustained retinal ganglion cells. Eur J Neurosci 22:2016-2026. CrossRef Medline

Zhang Y, Kim IJ, Sanes JR, Meister M (2012) The most numerous ganglion cell type of the mouse retina is a selective feature detector. Proc Natl Acad Sci U S A 109:E2391-E2398. CrossRef Medline

Zhao X, Chen H, Liu X, Cang J (2013) Orientation-selective responses in the mouse lateral geniculate nucleus. J Neurosci 33:12751-12763. CrossRef Medline

Zhu JJ, Uhlrich DJ, Lytton WW (1999) Burst firing in identified rat geniculate interneurons. Neuroscience 91:1445-1460. CrossRef Medline

Ziburkus J, Lo FS, Guido W (2003) Nature of inhibitory postsynaptic activity in developing relay cells of the lateral geniculate nucleus. J Neurophysiol 90:1063-1070. CrossRef Medline 